\title{
Convergence of European natural gas prices
}

\author{
Andrea Bastianin ${ }^{\mathrm{a}, *}$, Marzio Galeotti ${ }^{\mathrm{b}, \mathrm{d}}$, Michele Polo ${ }^{\mathrm{c}, \mathrm{d}}$ \\ a University of Milan-Bicocca, Italy \\ ${ }^{\mathrm{b}}$ University of Milan, Italy \\ ${ }^{\mathrm{C} B o c c o n i}$ University, Italy \\ ${ }^{\mathrm{d}}$ GREEN-Bocconi, Italy
}

\section{A R T I C L E I N F O}

\section{Article history:}

Received 18 December 2018

Received in revised form 16 April 2019

Accepted 23 May 2019

Available online 31 May 2019

\section{JEL classification:}

C22

L95

Q02

Q35

Q41

Keywords:

Convergence

Natural gas price

Trading hub

$\sigma$-convergence

Relative convergence

\begin{abstract}
A B S T R A C T
Over the period 2015-2050 the consumption of natural gas of European OECD countries is expected to grow more than the consumption of any other energy source. Although these countries are interconnected and in most cases share a common currency, their wholesale national gas markets are highly heterogeneous. We study the determinants of cross-country convergence of natural gas prices for industrial consumers in fourteen European countries. Our empirical analysis is based on the notions of pairwise, relative and $\sigma$-convergence. We show that there is evidence of pairwise price convergence and that some key characteristics of gas markets, such as the existence of trading hubs and the degree of interconnection, are positively associated with the existence of a convergence process. This result carries over to the notion of $\sigma$ convergence and is robust to a number of changes in the implementation of the statistical tests. The analysis of relative convergence points to the existence of price-growth convergence, while price-level convergence is not supported by the data. Lastly, we assess the short-run implications of price convergence focusing on the speed of reversion to equilibrium after a system-wide shock hits the cointegrating relation.
\end{abstract}

(c) 2019 Elsevier B.V. All rights reserved.

\section{Introduction}

In 2015 natural gas consumption of OECD Europe represented $13 \%$ of world consumption and $22 \%$ of their total primary energy consumption; moreover, in the 2015-2050 period it is expected to grow more than the consumption of any other energy source (EIA, 2017). Given its strategic importance, the functioning of the natural gas market is high on the agenda of European regulators who have devoted considerable effort to the creation of a single market for energy at least since the Single European Act of 1986. Three consecutive legislative packages were subsequently adopted between 1996 and 2009 with the aim of harmonizing and liberalizing the EU's internal energy market. As a result of these measures, new gas and electricity suppliers can enter the Member States' markets, while both industrial and domestic consumers are now free to choose their own suppliers. The appearance of a multitude of market

\footnotetext{
* Corresponding author at: Department of Economics, Management, and Statistics, University of Milan-Bicocca, Via Bicocca degli Arcimboldi, 8, Building U7, 20126 Milano, Italy.

E-mail address: andrea.bastianin@unimib.it (A. Bastianin).
}

operators that need to balance their positions has also prompted the development of trading hubs in several European countries (Heather, 2012; Miriello and Polo, 2015; Hulshof et al., 2016; del Valle et al., 2017). Whether regulatory reforms and the development of trading hubs have contributed to the integration of national markets or to the alignment of gas prices for both industrial and residential use is a highly debated topic ${ }^{1}$ (see e.g. Asche et al., 2017; Brau et al., 2010; Cremer and Laffont, 2002, and references therein).

In this paper we study the cross-country convergence of natural gas prices for industrial consumers in fourteen European countries relying on time series econometric techniques. These countries belong to the European Union, have interconnected natural gas markets, and in most cases share a common currency; however, their degree of interconnection and their wholesale national gas markets and trading hubs - where these exist - are highly heterogeneous in terms of

\footnotetext{
1 Notice however that, even in an integrated market, gas prices are not necessarily perfectly aligned; in fact, price differences might persist because of transportation costs (see e.g. Bachmeier and Griffin, 2006).
} 
maturity. We assess the association between the convergence of natural prices for industrial consumers, countries' characteristics, trading hub maturity and other institutional features.

Several papers have analyzed the impact of liberalizations on residential and industrial prices focusing on the process of integration and convergence across different locations. The methodology typically relies on the assessment of the Law of One Price (LOP) using cointegration analysis. See Barrett (1996), Fackler and Goodwin (2001) and Knetter and Slaughter (2001) for an overview of alternative methods used in spatial price analysis. In case of full integration of two markets, industrial consumers should pay the same price, once transaction and transportation costs are accounted for. For historical reasons, this strand of the literature has focused first on North America (see e.g., De Vany and Walls, 1993; King and Cuc, 1996; Serletis and Herbert, 1999; Cuddington and Wang, 2006; Park et al., 2008; Apergis et al., 2015) where in the mid-80s governments implemented several policies aimed at deregulating the market for natural gas. More recent are the contributions focusing on European gas markets (see e.g., Asche et al., 2002; Neumann et al., 2006; Robinson, 2007; Renou-Maissant, 2012; Growitsch et al., 2015; del Valle et al., 2017) or presenting international comparisons (Siliverstovs et al., 2005; Li et al., 2014).

This study is closely related to two papers. Robinson (2007) focused on annual retail natural gas prices for six EU Member States and showed that over the 1978-2003 period there is evidence of $\beta$-convergence, as well as of convergence toward the group average using the test proposed by Bernard and Durlauf $(1995,1996)$. Renou-Maissant (2012) tested the LOP and analyzed convergence across six European natural gas markets. Relying on half-yearly data for industrial consumers over the 1991-2001 period the author showed that there is an on-going process of price convergence, but that the strength of market integration varies through time and across countries. Compared with these two analyses, we consider a larger group of countries, use the less stringent concept of "pairwise convergence" (Pesaran, 2007) and rely on different econometric methods that have some advantages over those used by these authors. Since "pairwise convergence" is linked with the notion of $\sigma$-convergence, we present empirical evidence also on this issue. In addition, we consider the notion of relative convergence due to Phillips and Sul (2007) and we assess how convergence affects the speed of adjustment to equilibrium after a shock. Lastly, we study the association between the existence of price convergence and key characteristics of natural gas markets. Overall, we find evidence of convergence for the price paid by industrial consumers, in line with Robinson (2007) and Renou-Maissant (2012). The strength of this result however depends on the characteristics of national gas markets, as well as on the existence of gas hubs and on the degree of interconnection of the markets.

The rest of the paper is organized as follows. In Section 2 we describe the data and provide some background on the European gas market. Section 3 introduces different concepts of convergence. Section 4 presents the main empirical results. Section 5 discusses some robustness checks and extensions. Section 6 concludes. Further results and methodological details are provided in Appendix A.

\section{EU gas markets: data and background aspects}

\subsection{Data}

We consider before tax nominal prices paid for natural gas by industrial consumers in fourteen European countries, namely: Austria, Belgium, Germany, Denmark, Spain, France, Hungary, Ireland, Italy, Luxembourg, Netherlands, Sweden, Slovenia, United Kingdom. In line with previous studies we rely on before tax prices to avoid that fiscal policy might act as confounding factor in our convergence analysis (see e.g., Robinson, 2007; Renou-Maissant, 2012).
As shown in Fig. 1, each of these markets is interconnected with at least one of the other countries, which is the reason why the above countries were selected (see also Fig. A1 in Appendix A.2). We have sourced half-yearly natural gas prices for industrial consumers belonging to the medium consumption band (i.e., entities with consumption of 10,000-100,000 gigajoules per year) from Eurostat. The sample period runs from the first semester of 1991 through the first semester of 2017. Denoting semesters as " $h$ ", our data span the 1991:h1-2017: $h 1$ period, for a total of 53 observations per country. ${ }^{2}$

Robustness checks concerning our sample design are discussed in Section 5.1.

Fig. 2(a) shows that, that consistently with the notion that European gas markets are integrated, prices for industrial consumers are highly correlated; however, it is impossible to spot clear signs of convergence. Moreover, the spread of the series around the sample average tends to increase during episodes of high crude oil price volatility. This happens for instance in 2001, 2007/08 and 2012 and supports empirical studies showing that the gas pricing mechanism is still, at least to some extent, influenced by what happens in the crude oil market (Asche et al., 2013; Bachmeier and Griffin, 2006; Brown and Yücel, 2009; Hartley et al., 2008; Nick and Thoenes, 2014; Jadidzadeh and Serletis, 2017). However, we also point out that some recent studies showed that gas prices are mostly determined by their own fundamentals (Hulshof et al., 2016; Mu and Ye, 2018; Neumann, 2009). In Fig. 2(b)-(f) we show that, at least since 2007, industrial consumers in countries with more than tree interconnections or that host the most active trading hubs have experienced prices lower than the EU average.

\subsection{European markets for natural gas: background}

The analysis of price convergence for industrial gas consumers requires to understand how prices in European markets are set, how the inter-relation among them takes place and affects the price setting mechanisms. While in continental Europe gas trading is still largely based on long-term contracts indexed to the price of crude oil, there is evidence that gas-specific factors are becoming increasingly important (see e.g., Siliverstovs et al., 2005; Asche et al., 2017). Fig. 1 shows that as of 2017 all countries in our sample - except Luxembourg, Slovenia and Sweden - hosted at least one gas trading hub. Miriello and Polo (2015) provide a theoretical framework to analyze the patterns of development of wholesale gas markets and their relationship with the liberalization processes.

The process of liberalization of EU natural gas markets - led by the UK experience (Asche et al., 2013) - has involved three main legislative packages. With the First Gas Directive, promulgated in 1998 (1998/30/EC), gas markets were opened up to competition by facilitating the entry in the competitive segments of the industry. New common rules for transmission, distribution, supply and storage of natural gas were adopted. The Second Gas Directive (2003/55/EC) provided for the unbundling of the vertically integrated gas operators and made the transport networks of gas independent from production and supply. Industrial consumers were allowed to choose

\footnotetext{
2 Data are available from 1985, but before 1991 the effective sample size varies greatly and is often significantly shorter. Since the time series for Austria, Hungary, Sweden, and Slovenia start between 1991: $h 1$ and 1996:h1, we rely on the average growth rate of prices for the remaining countries to backcast missing observations. Let $p_{1, t}=\log \left(P_{1, t}\right)$ be the log-price for Sweden for $t=1996: h 1, \ldots, 2017: h 1$ and let $\overline{\Delta p_{t}}=(1 / 10) \sum_{j=1}^{10} \log \left(P_{j, t} / P_{j, t-1}\right)$ be the average price growth rate for Belgium, France, Germany, Denmark, Spain, Ireland, Italy, Luxembourg, Netherlands and United Kingdom. Then $P_{1, t-1}=\exp ^{\overline{\Delta p_{t}}} P_{1, t}$ for $t=1996: h 1, \ldots, 1991: h 2$. We also point out that because the percentage of missing prices for consumers belonging to lower or higher consumption bands is very high - often well above $50 \%$ - we cannot extend the analysis to these price series.
} 


$\begin{array}{lll}\text { ISO } & \text { Country } & \text { Hub } \\ \text { AT } & \text { Austria } & \text { CEGH } \\ \text { BE } & \text { Belgium } & \text { ZTP } \\ \text { DE } & \text { Germany } & \text { VHP NCG, } \\ \text { VHP-GASPOOL } \\ \text { GTF, NPTF } \\ \text { DK } & \text { Denmark } & \text { VIP PIRINEOS, PVB } \\ \text { ES } & \text { Spain } & \text { PEG NORD, TRS } \\ \text { FR } & \text { France } & \text { MPG } \\ \text { HU } & \text { Hungary } & \text { IBP } \\ \text { IE } & \text { Ireland } & \text { PSV } \\ \text { IT } & \text { Italy } \\ \text { LU } & \text { Luxembourg } & - \\ \text { NL } & \text { Netherlands } & \text { TTF } \\ \text { SE } & \text { Sweden } & - \\ \text { SI } & \text { Slovenia } & - \\ \text { UK } & \text { United Kingdom } & \text { NBP }\end{array}$

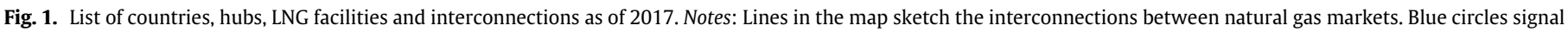
the presence of one or more Liquefied Natural Gas regasification facilities. Authors' elaborations using the 2017 ENTSOG Capacity map dataset (https://www.entsog.eu).

their suppliers since July 2004, while for household consumers the date was delayed to July 2007. The Third Gas Directive (2009/73/EC) improved the functioning of the internal energy market and resolved structural problems, plus unbundling of energy suppliers from network operators. ${ }^{3}$

The dynamics of the liberalization process over the 1975-2013 period is illustrated in Fig. 3, where we plot the OECD's Energy, Transport and Communications Regulation (ETCR) index for the natural gas markets of the countries in our sample (for details see Koske et al., 2015, and Appendix A.3). The ETCR index takes on values between zero and six, with lower values indicating fewer restrictions to competition. Data have annual sampling frequency and are available for the 1975-2013 period. As we can see, a downward sloping trend is clearly visible in Fig. 3; moreover, column 7 of Table 1 shows that in 2013 the ETCR index for natural gas did not exceed three for any market and was equal to zero for the UK, the country that started the liberalization process first. Column 6 shows that also the Product Marked Regulation (PMR) index - an overall score for natural gas, electricity, air, rail, road transport, post and telecommunications is always below three, indicating that reforms aimed at liberalizing network industries have been enacted by the governments of the countries in our sample.

Fig. 3 also highlights that the distribution of ETCR index for natural gas is highly dispersed around the median value over the whole period, thus suggesting that some heterogeneity in the level of competitiveness of different gas markets tends to persist. This fact is mirrored in the heterogeneity that characterizes the degree of maturity of European gas hubs. Following Heather and Petrovich (2017) these can be described according to "Score" and "Category" in Table 1, columns 3 and 4 . The subjective scoring system in column 3 evaluates three elements: commercial acceptance, political willingness

\footnotetext{
3 More recent EU legislation affecting natural gas markets includes: the Proposal for a Regulation "concerning measures to safeguard the security of gas supply and repealing Regulation (EU) No 994/2010" (COM(2016)52/F1) and the "Clean Energy For All Europeans" package, known as the "Winter Package", published on 30 November 2016, consisting of numerous legislative proposals together with accompanying documents, aimed at further completing the internal market for electricity and at implementing the Energy Union. The Energy Union strategy (COM(2015)0080) aims at giving consumers secure, sustainable, competitive and affordable energy. EU countries are therefore required to develop integrated national energy and climate plans that cover the five dimensions the make up the Energy Union for the period 2021 to 2030 These five dimensions are: (i) "Security, solidarity and trust", (ii) "fully-integrated internal energy market", (iii) "Energy efficiency", (iv) "Climate action - decarbonising the economy", $(v)$ "Research, innovation and competitiveness".
}

and cultural attitudes to trading. ${ }^{4}$ Higher scores identify mature hubs, while lower scores are associated to less active hubs. It is seen that mature hubs are hosted in the UK, Netherlands, France and Germany.

To sum up, more mature and liquid wholesale markets allow to manage efficiently balancing needs, adjusting internal imbalances of operators and the overall imbalances of the system, hedging price risk with financial instruments, preventing price manipulations and providing reliable price signals of the state of the system. When market liquidity is high, arbitrage opportunities in the traded gas are exploited by operators leading to a rapid convergence to the market equilibrium (Miriello and Polo, 2015). ${ }^{5}$

Indeed, market liquidity in the financial markets literature is intended to "indicate the ability to trade (a security) quickly at a price close to its consensus value" (see Foucault et al., 2013, pp. 325-326 on the relationship between poor market liquidity and limits to arbitrage). If the different national gas systems were completely isolated with no interconnection, but very liquid, we should observe prices to reflect country-specific fundamentals and idiosyncratic shocks. So long as these factors are different across countries, prices should not necessarily converge. Therefore, the relationship among national gas systems might also contribute to price convergence. These are affected by the level of interconnection that takes place through the international pipelines and the LNG terminals that allow intracommunity trades among member countries. As for the degree of interconnection, Barrett and Li (2002, p. 293) point out that market integration can be defined as tradability between markets. These authors also make clear that two markets without any direct linkage

\footnotetext{
4 For details see Heather and Petrovich (2017). Interestingly, this classification is consistent with that provided by EFET (2016) based on market statistics related with depth, liquidity and transparency of gas hubs (see Heather and Petrovich, 2017. Table 5 .

5 According to Miriello and Polo (2015) the liberalization has promoted a progressive fragmentation of the different market segments; consequently each operator manages smaller volumes and narrower portfolios of contracts. Then, the ability to compensate the gap between demand and supply of each individual contract by compensating imbalances of different sign within the portfolio is reduced. Balancing the system through direct trade among operators with different net positions has become a priority. The wholesale market in its initial phase has therefore developed to cope with these balancing needs. A more fragmented and more liquid wholesale market, in turn, has reduced the ability of large operators to manipulate the price, that has become a more reliable signal. These processes have made the wholesale markets an appealing second source of gas purchase as an alternative to long-term contracts, further pushing up liquidity. Lastly, price variability has required to manage price risk by developing financial instruments, the third stage of wholesale gas markets. See Miriello and Polo (2015) for details and evidence.
} 


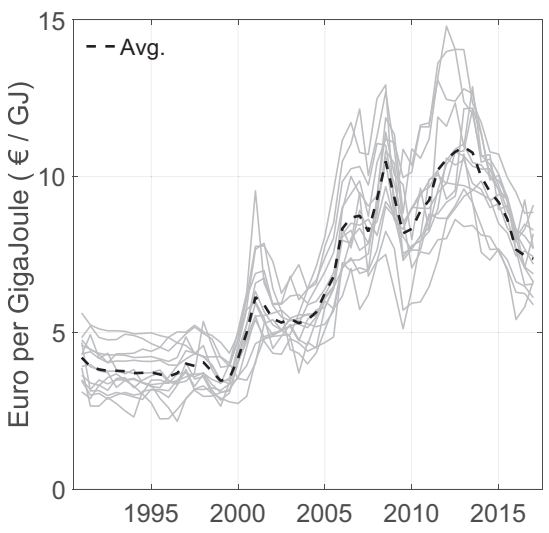

(a)

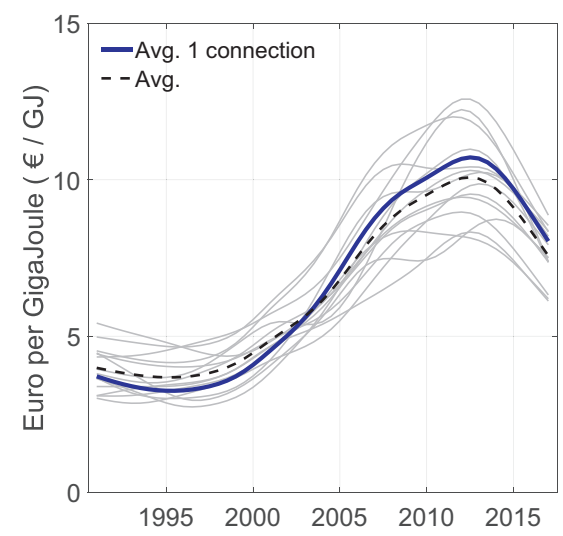

(d)

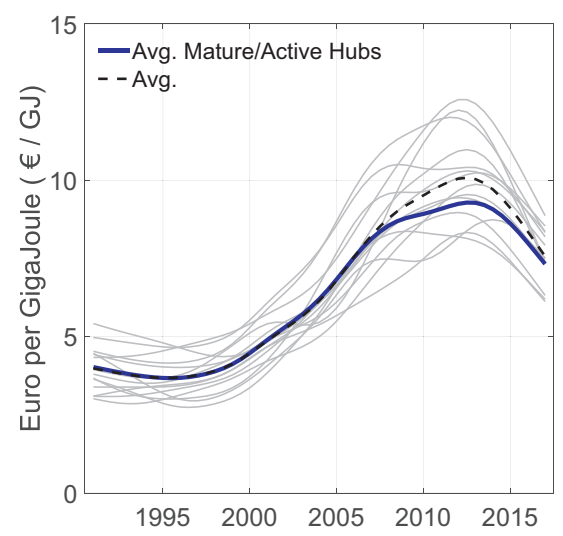

(b)

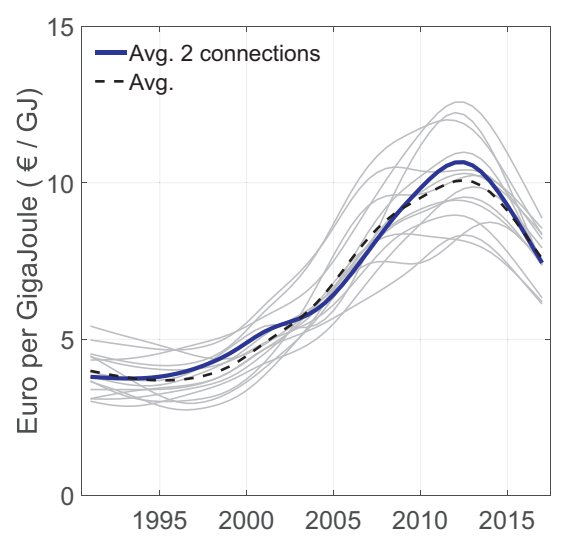

(e)

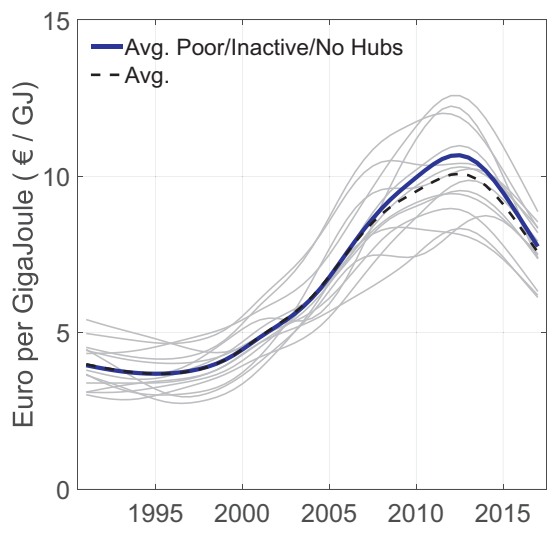

(c)

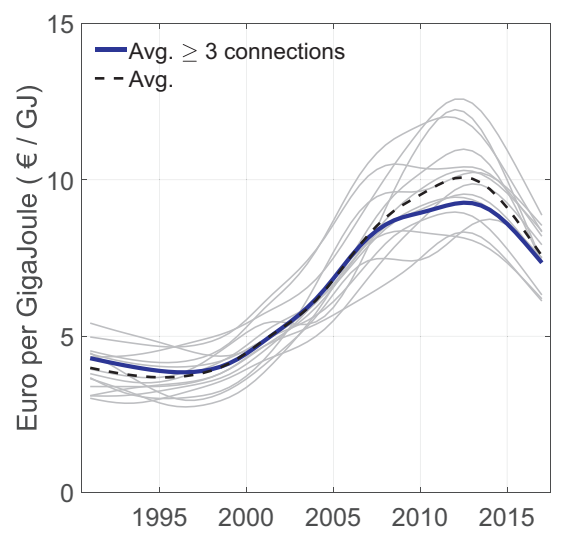

(f)

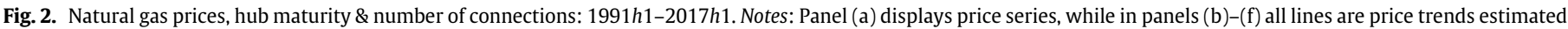

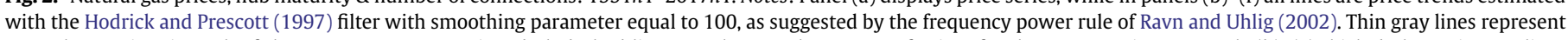

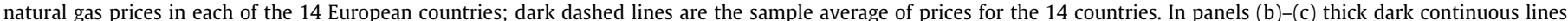

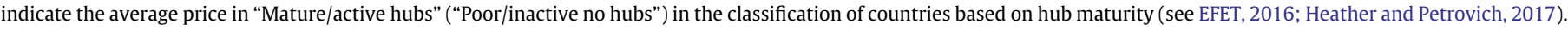
In panels (d)-(f) thick dark continuous lines identify the average price in hubs with a given number of connections (i.e. $1,2, \geq 3$ ).

can be integrated through third markets. A case in point, are two exporters that export to the same importing country.

Casual inspection of columns 3 and 5 of Table 1 suggests that hub maturity is positively correlated with the number of interconnections of a given gas market with the other countries in the sample. ${ }^{6}$

The map in Fig. 1 shows that only 6 out 14 countries had an operating Liquefied Natural Gas regassification facility in 2017. Appendix A.2 provides additional information on the technical physical capacity of European natural gas markets.

\footnotetext{
6 The Belgian and Austrian hubs are characterized by a very high level of interconnection that is not paired with an equivalent level of maturity. These two hubs are classified by Heather (2015, pp. 11-12) as "transit hubs". As pointed out by this author "their primary role is to facilitate the transit of large quantities of gas for onward transportation. Indeed, the two transit gas hubs of North-West Europe, Zeebrugge in Belgium and Baumgarten in Austria, have the capacity between them to handle (...) around 45\% of the demand in the downstream countries they provide gas to. This makes these two locations very important in the physical context of gas deliveries of Western Europe; however, the nature of their formation means that trading has not developed as much as in neighbouring hubs."
}

\section{Price convergence: concepts and theoretical background}

\subsection{Theoretical background}

We analyze cross-country price convergence relying on log-price differentials:

$d_{i j, t}=\log \left(\frac{P_{i, t}}{P_{j, t}}\right)=p_{i, t}-p_{j, t} \quad$ for $i, j=1, \ldots, N \quad$ and $\quad i \neq j$

where $p_{i, t} \equiv \log P_{i, t}$ and $P_{i, t}$ is the before tax price of natural gas for industrial consumers in country $i$. Bernard and Durlauf $(1995,1996)$ proposed the following definition of convergence:

$\lim _{H \rightarrow \infty} E\left(p_{i, t+H}-p_{j, t+H} \mid \mathcal{I}_{t}\right)=0 \quad$ for $\quad H>0$

where $\mathcal{I}_{t}$ is the information set at time $t$ containing current and past information on prices. In this setting, price convergence requires that the long-term forecast of $d_{i j, t}$ tends to zero as the forecast horizon $H$ increases. This implies that a necessary, but not sufficient condition 


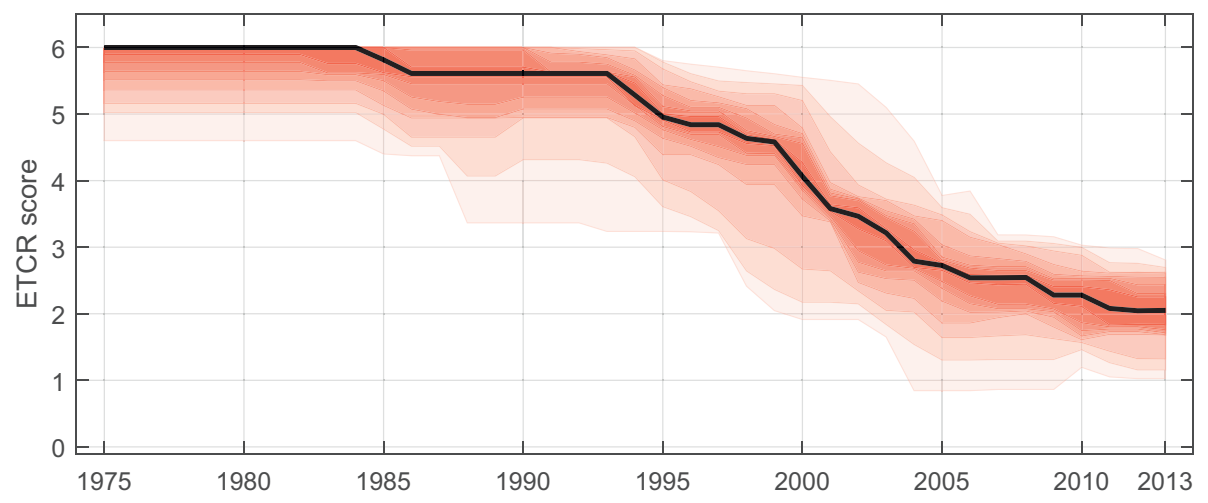

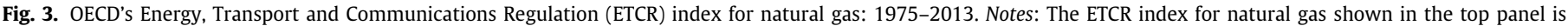

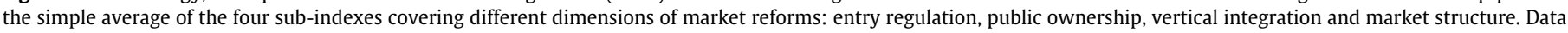

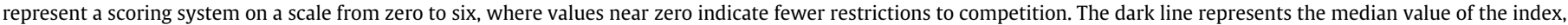
the shaded area is delimited by the 10th and 90th percentile of the distribution of the index across countries.

Source: Source: Authors' elaboration on data from Koske et al. (2015)

for prices in countries $i$ and $j$ to converge, is that they are cointegrated with cointegrating vector $[1,-1]^{\prime}$. Suppose that the log-price of natural gas in each country can be written as:

$p_{i, t}=\gamma_{i}+\beta_{i} t+\psi_{i, t} \quad$ for $\quad i=1, \ldots, N$

Eq. (3) expresses $p_{i, t}$ as the sum of a country fixed effect $\left(\gamma_{i}\right)$, a deterministic trend component $\left(\beta_{i} t\right)$ and an error term $\left(\psi_{i, t}\right)$ that can be either integrated of order one, $I(1)$, or stationary. If prices in country $i$ and $j$ are cointegrated with cointegrating vector $[1,-1]^{\prime}$, there exists a linear combination $z_{t}=p_{i, t}-p_{j, t}$ that is stationary or trend stationary. The convergence condition in Eq. (2) can therefore be written as the limit of:

$E\left(p_{i, t+H}-p_{j, t+H} \mid \mathcal{I}_{t}\right)=\left(\gamma_{i}-\gamma_{j}\right)+\left(\beta_{i}-\beta_{j}\right)(t+H)+E\left(\psi_{i, t+H}-\psi_{j, t+H} \mid \mathcal{I}_{t}\right)$

Table 1

Descriptive statistics for the European natural gas markets.

\begin{tabular}{|c|c|c|c|c|c|c|}
\hline \multirow[b]{2}{*}{ (1) } & \multirow[b]{2}{*}{ (2) } & \multicolumn{3}{|l|}{ Hub } & \multicolumn{2}{|c|}{ ETCR score } \\
\hline & & (3) & (4) & (5) & (6) & $(7)$ \\
\hline iso & Country & Score & Category & Connections & PMR & Gas \\
\hline AT & Austria & 13.5 & Poor & 4 & 1.5 & 2.2 \\
\hline $\mathrm{BE}$ & Belgium & 17.5 & Active & 5 & 1.8 & 1.7 \\
\hline $\mathrm{DE}$ & Germany & 19 & Mature & 6 & 1.3 & 1.2 \\
\hline DK & Denmark & 14 & Poor & 2 & 1.6 & 2.6 \\
\hline ES & Spain & 13.5 & Poor & 1 & 1.6 & 1.1 \\
\hline FR & France & 18.5 & Mature & 3 & 2.5 & 2.5 \\
\hline $\mathrm{HU}$ & Hungary & 9 & Poor & 1 & 1.7 & 1.7 \\
\hline IE & Ireland & - & - & 1 & 2.2 & 3.0 \\
\hline IT & Italy & 15 & Active & 2 & 2.0 & 1.9 \\
\hline LU & Luxembourg & - & - & 2 & 2.7 & 2.6 \\
\hline NL & Netherlands & 19.5 & Mature & 3 & 1.6 & 2.3 \\
\hline SE & Sweden & - & - & 1 & 1.9 & 1.7 \\
\hline SI & Slovenia & - & - & 2 & 2.9 & 2.8 \\
\hline UK & UK & 20 & Mature & 3 & 0.8 & 0.0 \\
\hline
\end{tabular}

Notes: Columns 3, 4, 5 indicate the 2016 classification of countries based on hub maturity (see EFET, 2016; Heather and Petrovich, 2017), where “-" denotes that there are no information on the relevant hub or that there is no hub. Columns 6 and 7 report the 2013 value of indices sourced from the OECD's Energy, Transport and Communications Regulation (ETCR) dataset (Koske et al., 2015). These indices represent a scoring system on a scale from zero to six, where values near zero indicate fewer restrictions to competition. Column 6 shows the Product Market Regulation index ("PMR"); this is an overall score for seven network industries: gas, electricity, air, rail, road transport post and telecommunications. Column 7 shows the ETCR index for the natural gas market ("Gas"). We show the 2013 values of the ETCR indices because they represent they were released for the last time in that year.
If $\psi_{i, t}$ and $\psi_{j, t}$ are zero-mean independent stationary processes, it follows that $\lim _{H \rightarrow \infty} E\left(\psi_{i, t+H}-\psi_{j, t+H} \mid \mathcal{I}_{t}\right)=E\left(\psi_{i, t}-\psi_{j, t}\right)=0$.

In this case, natural gas prices in country $i$ and $j$ converge if $\gamma_{i}=\gamma_{j}$ and $\beta_{i}=\beta_{j}$. If instead $\psi_{i, t}$ and $\psi_{j, t}$ are $I(1)$, we also require the two prices to share a common stochastic trend, that is: $\psi_{i, t}=\psi_{j, t}$. These conditions imply that economies $i$ and $j$ are equal almost in every respect (i.e., the "poolability" restriction: $\gamma_{i}=\gamma_{j}$ ), that the two price series share a deterministic trend (i.e., the "cotrending" restriction: $\beta_{i}=\beta_{j}$ ) and, in case of a unit root in the price series, that they are cointegrated $\left(\psi_{i, t}=\psi_{j, t}\right)$. Of these conditions the "poolability" restriction $\left(\gamma_{i}=\gamma_{j}\right)$, is the most unlikely to be satisfied. In addition, assessing cointegration involves a pre-test bias due to the fact that the individual price series need to be preliminary tested for the presence of a unit root. However, if prices are generated by a "near unit root process", standard unit-root tests have low power against the alternative hypothesis and hence lead to biased second-stage inferences (Cavanagh et al., 1995; Elliott, 1998).

Pesaran (2007) showed that a less stringent formulation of convergence is based on the conditional probability of observing an arbitrarily small log-price differential. The concept of "pairwise convergence" implies that prices in country $i$ and $j$ converge if:

$\operatorname{Pr}\left(\left|p_{i, t+H}-p_{j, t+H}\right|<C \mid \mathcal{I}_{t}\right)>\pi \quad$ for $C>0, \quad 0 \leq \pi<1, \quad \forall H>0$

Condition (5) is satisfied if the log-price differential does not display stochastic nor deterministic trends, that is $\beta_{i}=\beta_{j}$ and $\psi_{i, t}=\psi_{j, t}$ if prices are $I(1)$. However, "pairwise convergence" does not require "poolability" $\left(\gamma_{i}=\gamma_{j}\right)$, does not rely on unit root tests for the individual price series and hence allows to eschew pre-test issues. In fact, this notion of convergence allows two countries to be different (with country heterogeneity captured by $\gamma_{i}$ and $\gamma_{j}$ ) and requires only testing for the absence of unit roots and linear deterministic trends in the log-price differential. Extension to a multi-country setting requires pairwise convergence across all country pairs. ${ }^{7}$

\footnotetext{
7 In a multi-country setting condition (5) is (see Pesaran, 2007):
}

$\operatorname{Pr}\left\{\bigcap_{i=1, \ldots, N-1}\left|p_{i, t+H}-p_{j, t+H}\right|<C \mid \mathcal{I}_{t}\right\}>\pi$ for $C>0, \quad 0 \leq \pi<1, \forall H>0$. 
Interestingly, also Cuddington and Wang (2006) studied the timeseries properties of log-price differentials to assess the degree of integration of US natural gas markets. However, compared with their approach, the theoretical assumptions and statistical properties underlying the notion of "pairwise convergence" have more solid methodological foundations that have been deeply investigated by Pesaran (2007) and Pesaran et al. (2009).

\subsection{Tests of pairwise price convergence}

Tests for pairwise convergence involve two distinct steps. First, since two prices converge if $d_{i j, t}$ is stationary with a constant mean, we need to test for the presence of a unit root in the log-price differential across all country pairs. Next, in the case of rejection of the null hypothesis of a unit root in $d_{i j, t}$, we check the cotrending condition, namely $\beta_{i}=\beta_{j}$. This is carried out, with an OLS regression of $d_{i j, t}$ on a constant and a linear trend. If the trend is not statistically distinguishable from zero, we conclude that prices in market $i$ and $j$ converge. Our baseline results are based on three tests for a unit root in $d_{i j, t}$, namely the Augmented Dickey-Fuller test (Dickey and Fuller, 1979) (ADF), the Generalized Least Squares Dickey-Fuller test (Elliott et al., 1996) (DF-GLS) and the Augmented Dickey-Fuller Weighted Symmetric test (Park and Fuller, 1995) (ADF-WS). The DF-GLS and the ADF-WS tests have been shown to be superior to the ADF test (Leybourne et al., 2005; Pantula et al., 1994).

Denote by $U R$ the test of the null hypothesis of a unit root $H_{0}$ : $d_{i j, t} \sim I(1)$ against the alternative that $d_{i j, t}$ is stationary, where $U R$ is one of the three tests discussed above, that is $U R=A D F, D F-G L S$, ADF-WS. Denoting the test carried out on observations $t=1, \ldots, T$ as $U R_{i j, T}$ and its critical value of size $\alpha$ as $C V_{T, \alpha}$, the null hypothesis of "price divergence" is rejected if $U R_{i j, T}<C V_{T, \alpha}$. Noting that $\lim _{T \rightarrow \infty} \operatorname{Pr}\left(U R_{i j, T}<C V_{T, \alpha} \mid H_{0}\right)=\alpha$ and letting $Z_{i j, T}=1$ if $U R_{i j, T}<$ $C V_{T, \alpha}$, the fraction of the $N(N-1) / 2$ pairs for which the unit root is rejected can be written as:

$\bar{Z}_{N T}=\frac{2}{N(N-1)} \sum_{i=0}^{N-1} \sum_{j=1+i}^{N} Z_{i j, T}$

Pesaran (2007) showed that $\bar{Z}_{N T}$ is a consistent estimator of $\alpha$ for large $N$ and $T$. Therefore, under the null hypothesis of a unit root in the price differentials we have: $\lim _{T \rightarrow \infty} E\left(\bar{Z}_{N T} \mid H_{0}\right)=\alpha$. It follows that if price convergence is supported by the data, the null hypothesis of a unit root in the price differential should be rejected for a large number of country pairs: hence, $\bar{Z}_{N T}$ should tend to unity and be much larger than the size of the test $\alpha$. On the contrary, if the null of "price divergence" cannot be rejected for a large number of price differentials, $\bar{Z}_{N T}$ is expected to be close to the size of the test $\alpha$.

\subsection{From pairwise to $\sigma$-convergence}

Pesaran (2007) showed that starting from squared log-price differentials it is possible to construct an average measure of convergence/divergence that can be used to investigate whether the cross-section variance of prices decreases over time. In particular, the cross-section standard deviation of log-prices is proportional to the squares of the log-price differentials, $d_{i j, t}$, averaged across country pairs. That is:

$$
\begin{aligned}
D_{t}^{2} & =\frac{2}{N(N-1)} \sum_{i=1}^{N-1} \sum_{j=i+1}^{N}\left(d_{i j, t}\right)^{2} \\
& =2 \times\left\{\frac{\sum_{i}^{N}\left(p_{i, t}-\bar{p}_{t}\right)^{2}}{N-1}\right\}=2 \hat{\sigma}_{t}^{2}
\end{aligned}
$$

where $\bar{p}_{t}=N^{-1} \sum_{i=1}^{N} p_{i, t}$ and $D_{t}$ is proportional to the cross-section standard deviation of prices, $\hat{\sigma}_{t}$. The notion of $\sigma$-convergence can thus be investigated tracking $\hat{\sigma}_{t}$ or other measures of dispersion over time.

\subsection{Testing relative convergence}

Phillips and Sul (2007) proposed a very flexible test of "relative convergence" that is valid under a less restrictive set of assumptions than those needed to satisfy the notion of pairwise and $\sigma$ convergence (see Li et al., 2010, 2014; Mu and Ye, 2018, for applications to coal and gas markets). Relative convergence means that two series share the same stochastic or deterministic trend in the long-run and hence their ratio will eventually converge to unity. Interestingly, this notion of convergence allows for periods of transitional divergence: what matters is that in the long-run the two series converge to the common trend. Moreover, this approach can be used to investigate whether the convergence process involves the log-level of prices or their growth rates. The starting point of the Phillips and Sul (2007) test for relative convergence is a non-linear panel model for prices:

$p_{i t}=\delta_{i t} \mu_{t}$

where $\mu_{t}$ is common stochastic or deterministic trend and $\delta_{i t}$ is country specific slope that captures a time-varying factor loading coefficient attached to $\mu_{t}$. The role of $\delta_{i t}$ is that of a vector of weights that measure the distance between the price of natural gas in country $i$ and the common trend $\mu_{t}$. Relative convergence is formally defined as:

$\operatorname{plim}_{t \rightarrow \infty} \frac{p_{i t}}{p_{i j}} \rightarrow 1 \quad$ for $i \neq j$

where "plim" denotes convergence in probability. The Phillips and Sul (2007) test is based on the estimation of the following regression model:

$\log \left(\frac{H_{1}}{H_{t}}\right)-2 \log \log t=\lambda_{0}+\lambda_{1} \log t+u_{t}$

where $H_{t}=N^{-1} \sum_{i=1}^{N}\left(h_{i t}-1\right)^{2}$ is the sample transition distance and $h_{i t}=p_{i t} /\left[N^{-1} \sum_{i=1}^{N} p_{i t}\right]$ is the relative transition curve for $t=$ $\lceil r T\rceil,\lceil r T\rceil+1, \ldots, T$ for $r=0.3$. The null hypothesis of convergence $H_{0}: \lambda_{1} \geq 0$ against $H_{1}: \lambda_{1}<0$ can be tested with a standard one-sided t-test based on heteroskedasticity and autocorrelation consistent standard errors (Newey and West, 1987). The magnitude of the slope coefficient on $\log t$ is also of interest. In fact, it can be shown that we have growth convergence if $0 \leq \lambda_{1}<2$ and convergence in log-level if $\lambda_{1} \geq 2$.

\section{Results}

In this section we first present results concerning pairwise convergence, then we analyze $\sigma$ - and relative convergence. Robustness checks and further results are presented in Section 5.

\subsection{Pairwise convergence}

Formal statistical tests of pairwise convergence are presented in Table 2. For the deterministic components of the unit root tests, we consider two cases: we include only the intercept ("const") or add also a linear trend, but only if it is significant at the $5 \%$ level ("const/trend"). We estimate the optimal number of lags included in the test equation with either Akaike (AIC) or Schwarz (SIC) Information Criterion. With 
Table 2

Pairwise convergence tests - 1991:h1-2017:h1.

\begin{tabular}{|c|c|c|c|c|c|c|c|c|}
\hline & \multicolumn{4}{|l|}{$5 \%$} & \multicolumn{4}{|l|}{$10 \%$} \\
\hline & (1) & $(2)$ & (3) & (4) & (5) & (6) & (7) & $(8)$ \\
\hline & AIC & $\% t$ & SIC & $\% t$ & AIC & $\% t$ & SIC & $\% t$ \\
\hline \multicolumn{9}{|l|}{ (a) ADF test } \\
\hline Const & 37.4 & 44.1 & 35.2 & 50.0 & 56.0 & 39.2 & 45.1 & 46.3 \\
\hline Const/trend & 49.5 & 33.3 & 45.1 & 39.0 & 68.1 & 32.3 & 63.7 & 32.8 \\
\hline \multicolumn{9}{|c|}{ (b) DF-GLS test } \\
\hline Const & 52.7 & 43.8 & 47.3 & 44.2 & 72.5 & 37.9 & 69.2 & 38.1 \\
\hline Const/trend & 52.7 & 43.8 & 48.4 & 43.2 & 70.3 & 39.1 & 64.8 & 40.7 \\
\hline \multicolumn{9}{|c|}{ (c) ADF-WS test } \\
\hline Const & 60.4 & 40.0 & 60.4 & 40.0 & 72.5 & 37.9 & 72.5 & 37.9 \\
\hline Const/trend & 53.8 & 44.9 & 53.8 & 44.9 & 70.3 & 39.1 & 70.3 & 39.1 \\
\hline
\end{tabular}

Notes: Each panel shows in columns 1, 3, 5, and 7 the percentage of the 91 log-price differentials $\left(d_{i j, t}\right)$ for which the null hypothesis of unit root is rejected $\left(\bar{Z}_{N T}\right)$. In the case of rejection of the null hypothesis (i.e. for stationary log-price differentials), columns $2,4,6$, and 8 show the percentage of log-price differential for which the hypothesis of a non-significant trend is not rejected. Student tests of the significance of the linear trend are conducted at the 5\% significance level in a regression of $d_{i j, t}$ on a constant and a linear trend (the test is carried out only when the null hypothesis of unit root is rejected). Convergence between prices is supported by the data when $\bar{Z}_{N T}$ is large relative to the significance level of the unit root test $-5 \%$ or $10 \%$ in this table - and the number of trend stationary series relatively low (i.e. the \% in the "\% $t$ " column is high). Each panel presents two cases for the deterministic component of the unit root test: "const" indicates that we included only the intercept; "const/trend" indicates that we included a linear trend only if it is significant at the $5 \%$ level. The lag length of test equations has been selected either with the Akaike or with the Schwarz information criterion, denoted as AIC and SIC, respectively. The maximum lag order is set equal to 4 that corresponds to two years. The three tests are the standard Augmented Dickey Fuller (ADF, Dickey and Fuller, 1979), the DF-GLS of Elliott et al. (1996) and the ADF-WS of Park and Fuller (1995). Critical values for the ADF test are provided by MacKinnon (1996), while those for the DF-GLS and ADF-WS have been calculated by the authors using the response surface regressions in Cheung and Lai (1998) and Cheung and Lai (2009), respectively.

$N=14$ countries, we have a total of $N(N-1) / 2=91 \log$-price differentials to test. Log-price differentials are shown in Appendix A.4.1.

Pairwise price convergence is supported by the data when the null hypothesis is rejected a large number of times relative to the nominal size of the unit root test that in Table 2 is $5 \%$ or $10 \%$. Columns $1,3,5$ and 7 show that independently of the significance level, lag order, or exogenous variables included in the test equation, the fraction of rejections, $\bar{Z}_{N T}$, is always well above the nominal size of the test. At $5 \%(10 \%)$ significance level $\bar{Z}_{N T}$ ranges from $33.3 \%$ (37.9\%) to $60.4 \%$ (72.5\%). A high percentage of rejections of the null hypothesis of a unit root is however not enough to safely conclude that European gas prices have converged; in addition, log-price differentials should not feature any deterministic trend, but move around a constant mean. Columns 2, 4, 6 and 8 show the percent of log-price differentials for which the null hypothesis of a non-significant trend cannot be rejected. Student tests of the significance of the linear trend are conducted at the $5 \%$ significance level in a regression of $d_{i j, t}$ on a constant and a linear trend. Notice that the test is carried out only when the null hypothesis of unit root is rejected. There is evidence of convergence if the percentage of trend stationary series is relatively low (i.e. if the percentage in the "\% $t^{\prime \prime}$ column is high). It can be seen that in all cases such fraction never exceeds 50\%, implying that the percentage of trend stationary series is relatively high. The existence of many trend stationary log-price differentials does not support convergence of prices across the countries in our sample.

\subsubsection{Pairwise convergence: structural breaks and sub-sample analysis}

Overall, Table 2 does not answer the question of whether industrial natural gas prices have converged: while price differentials in most cases do not have a unit root, many of them are stationary around a linear trend. These results rely on relatively standard unit
Table 3

Pairwise convergence tests - before \& after Euro introduction.

\begin{tabular}{|c|c|c|c|c|c|c|c|c|}
\hline & \multicolumn{4}{|l|}{$5 \%$} & \multicolumn{4}{|l|}{$10 \%$} \\
\hline & \multirow{2}{*}{$\frac{(1)}{\mathrm{AIC}}$} & \multirow{2}{*}{$\frac{(2)}{\% t}$} & \multirow{2}{*}{$\frac{(3)}{\text { SIC }}$} & \multirow{2}{*}{$\frac{(4)}{\% t}$} & \multirow{2}{*}{$\frac{(5)}{\mathrm{AIC}}$} & \multirow{2}{*}{$\frac{(6)}{\% t}$} & \multirow{2}{*}{$\frac{(7)}{\mathrm{SIC}}$} & \multirow{2}{*}{$\frac{(8)}{\% t}$} \\
\hline & & & & & & & & \\
\hline \multicolumn{9}{|c|}{ (a) ADF test: 1991:h1-2001:h2 } \\
\hline Const & 20.9 & 78.9 & 25.3 & 73.9 & 27.5 & 80.0 & 35.2 & 71.9 \\
\hline Const/trend & 25.3 & 65.2 & 35.2 & 53.1 & 36.3 & 60.6 & 44.0 & 57.5 \\
\hline \multicolumn{9}{|c|}{ (b) ADF test: 2002:h1-2017:h1 } \\
\hline Const & 26.4 & 66.7 & 24.2 & 72.7 & 41.8 & 57.9 & 38.5 & 60.0 \\
\hline Const/trend & 33.0 & 53.3 & 30.8 & 57.1 & 50.5 & 47.8 & 48.4 & 47.7 \\
\hline \multicolumn{9}{|c|}{ (c) DF-GLS test: 1991:h1-2001:h2 } \\
\hline Const & 24.2 & 86.4 & 28.6 & 73.1 & 36.3 & 72.7 & 44.0 & 62.5 \\
\hline Const/trend & 31.9 & 65.5 & 35.2 & 59.4 & 40.7 & 64.9 & 51.6 & 53.2 \\
\hline \multicolumn{9}{|c|}{ (d) DF-GLS test: 2002: h1-2017:h1 } \\
\hline Const & 40.7 & 56.8 & 34.1 & 61.3 & 58.2 & 50.9 & 48.4 & 54.5 \\
\hline Const/trend & 45.1 & 51.2 & 42.9 & 48.7 & 60.4 & 49.1 & 57.1 & 46.2 \\
\hline \multicolumn{9}{|c|}{ (e) ADF-WS test: 1991:h1-2001:h2 } \\
\hline Const & 34.1 & 74.2 & 34.1 & 74.2 & 28.6 & 84.6 & 28.6 & 84.6 \\
\hline Const/trend & 27.5 & 92.0 & 27.5 & 92.0 & 30.8 & 78.6 & 30.8 & 78.6 \\
\hline \multicolumn{9}{|c|}{ (f) ADF-WS test: 2002:h1-2017:h1 } \\
\hline Const & 50.5 & 56.5 & 50.5 & 56.5 & 54.9 & 52.0 & 54.9 & 52.0 \\
\hline Const/trend & 47.3 & 60.5 & 47.3 & 60.5 & 59.3 & 48.1 & 59.3 & 48.1 \\
\hline
\end{tabular}

Notes: The maximum lag order is set equal to 2 that corresponds to one year; for further details see notes to Table 2 .

root tests that have power against the alternative of trend stationarity. To take into account the possibility of structural breaks, we now analyze how pairwise convergence has evolved over time and in response to key policy events.

More precisely, we first consider unit root tests that allow for structural breaks in the price series and then we repeat the analysis over different sub-samples based on key economic events. We notice that unit root tests that allow for structural breaks in the price series exploit the entire span of data, whereas the analysis over different sub-samples is expected to reduce the power of unit root tests (Pantula et al., 1994) because shorter time series are involved. Therefore, beside providing an estimate of the break date, tests that allow for structural breaks should go some way to addressing the small sample issue. Nevertheless, we point out that analyzing how pairwise convergence has evolved over sub-samples has the advantage of leaving the choice of the break dates to the analyst that can therefore select what he/she believes are significant economic events.

All in all, these observations suggest that the two approaches involve a trade-off between the power of the test and its economic content. ${ }^{8}$

4.1.1.1. The Zivot and Andrews (2002) test. Perron (1989) showed that standard tests cannot reject the unit root null hypothesis when the true data generating process is that of a stationary series that fluctuates around a time trend with a one-time structural break that changes its slope and/or its intercept. The author proposed a test where the null hypothesis is that of a series with a unit root, while the alternative hypothesis is that the series is stationary around a broken trend. In this case, the date of the structural break is exogenously determined and the researcher has to pick a single observation that identifies the time period when the trend changes

\footnotetext{
8 Further results appear in Appendix A.4.2 where we also report evidence of pairwise convergence based on the unit root test due to Kapetanios et al. (2003) that has power against the alternative that the log-price differential is generated by a smooth transition autoregressive model. Moreover, in Section A.4.3 of Appendix A we investigate pairwise convergence across different country groups.
} 
intercept, slope or both. Zivot and Andrews (2002) showed that this procedures can be improved if the break date is estimated from the data. We implement this second approach and test the null hypothesis that a log-price differential can be approximated by a unit root process with drift, against the alternative hypothesis that the series is stationary around a broken trend.

The Zivot-Andrews test, identifies the second semester of 2001 as a breakpoint. Interestingly, this corresponds to a key policy event for several countries in our sample where Euro coins and banknotes replaced national currencies and entered in circulation on 1 January 2002. Results of the Zivot-Andrews test confirm that pairwise convergence is supported by the data. In fact, the null hypothesis is rejected a large number of times: the percentage of rejections is 4.7-7.6 times larger than the nominal size of the test.

4.1.1.2. Euro introduction - 2002. Since the introduction of the Euro in 2002 has been identified as the date of a possible structural break, Table 3 tests for pairwise convergence both before and after 2002 . In both time periods the fraction of rejections of the unit root null hypothesis is much higher that the nominal size of the test. This result is robust across specifications and unit root tests. Interestingly, we can also observe that after the Euro was introduced the fraction of rejections always increases. Moreover, looking at columns $2,4,6$ and 8 we see that the percentage of log-price differentials for which the null hypothesis of a non-significant trend cannot be rejected is very high. However, we also see that this percentage tends to decrease during the second period. Overall, Table 3 suggests that there is evidence of pairwise convergence. Whether this can be entirely attributed to the Euro introduction is not clear, not only because we cannot disentangle the effect of this event from other concurrent events, but also because the unit root tests and the tests for the significance of linear trends provide conflicting evidence in the two sub-samples.

4.1.1.3. Great Recession, Eurostat's methodology and more - 2007. There are three main reasons why in 2007 there might be a break in the natural gas price series. First, the National Bureau of Economic Analysis dates the start of the Great Recession in December 2007 and it is well known that the crude oil price rally in 2008/09 is one of the factors that has contributed to this event (Stock and Watson, 2012). Second, the rapid development of shale gas and shale oil production have affected the energy markets worldwide (Auping et al., 2016; Caporin and Fontini, 2017; Kilian, 2017; Koster and van Ommeren, 2015; Saussay, 2018). Lastly, a more practical concern is related with data collection procedures. Eurostat introduced a new methodology to collect natural gas price data in 2007. The new methodology uses "consumption bands" instead of "consumers standards". For the 1991: $h 1-2006: h 2$ period we use prices for I3-1 industrial consumers (i.e. annual consumption $41,860 \mathrm{GJ}$ ), while from $2007: h 1$ we use prices for Band I3 consumers (i.e., consumption of 10,000-100,000 gigajoules per year). Further robustness checks concerning the change in Eurostat's methodology are discussed in Section 5.1.

Table 4 shows evidence of pairwise convergence before and after 2007. Moreover, both the fraction of rejections of the null hypothesis of a unit root and the fraction of price differentials that do not display statistically significant linear trends increases after 2007. These facts are consistent with the view that over time different factors and policy initiatives have contributed to a higher integration of European natural gas markets. ${ }^{9}$

\footnotetext{
9 This is confirmed also by the analysis of pairwise convergence before and after the Second Gas Directive of 2004 reported in Section A.4.2 of Appendix A.
}

Table 4

Pairwise convergence tests - before \& after 2007.

\begin{tabular}{|c|c|c|c|c|c|c|c|c|}
\hline & \multicolumn{4}{|l|}{$5 \%$} & \multicolumn{4}{|l|}{$10 \%$} \\
\hline & (1) & (2) & (3) & $(4)$ & $(5)$ & (6) & (7) & $(8)$ \\
\hline & AIC & $\% t$ & SIC & $\% t$ & AIC & $\% t$ & SIC & $\% t$ \\
\hline \multicolumn{9}{|c|}{ (a) ADF test: 1991:h1-2006:h2 } \\
\hline Const & 15.4 & 64.3 & 23.1 & 66.7 & 25.3 & 60.9 & 30.8 & 64.3 \\
\hline Const/trend & 22.0 & 45.0 & 23.1 & 66.7 & 38.5 & 40.0 & 37.4 & 52.9 \\
\hline \multicolumn{9}{|c|}{ (b) ADF test: 2007:h1-2017:h1 } \\
\hline Const & 30.8 & 60.7 & 29.7 & 59.3 & 48.4 & 68.2 & 47.3 & 67.4 \\
\hline Const/trend & 37.4 & 50.0 & 35.2 & 50.0 & 54.9 & 60.0 & 54.9 & 58.0 \\
\hline \multicolumn{9}{|c|}{ (c) DF-GLS test: 1991:h1-2006:h2 } \\
\hline Const & 24.2 & 63.6 & 29.7 & 63.0 & 44.0 & 52.5 & 47.3 & 53.5 \\
\hline Const/trend & 26.4 & 58.3 & 30.8 & 60.7 & 42.9 & 53.8 & 42.9 & 59.0 \\
\hline \multicolumn{9}{|c|}{ (d) DF-GLS test: 2007:h1-2017:h1 } \\
\hline Const & 36.3 & 69.7 & 35.2 & 71.9 & 51.6 & 63.8 & 45.1 & 65.9 \\
\hline Const/trend & 41.8 & 60.5 & 41.8 & 60.5 & 53.8 & 61.2 & 49.5 & 60.0 \\
\hline \multicolumn{9}{|c|}{ (e) ADF-WS test: 1991:h1-2006:h2 } \\
\hline Const & 34.1 & 58.1 & 34.1 & 58.1 & 44.0 & 55.0 & 44.0 & 55.0 \\
\hline Const/trend & 28.6 & 69.2 & 28.6 & 69.2 & 40.7 & 59.5 & 40.7 & 59.5 \\
\hline \multicolumn{9}{|c|}{ (f) ADF-WS test: 2007:h1-2017:h1 } \\
\hline Const & 48.4 & 65.9 & 48.4 & 65.9 & 44.0 & 67.5 & 44.0 & 67.5 \\
\hline Const/trend & 44.0 & 72.5 & 44.0 & 72.5 & 45.1 & 65.9 & 45.1 & 65.9 \\
\hline
\end{tabular}

Notes: The maximum lag order is set equal to 2 that corresponds to one year; for further details see notes to Table 2 .

\section{2. $\sigma$-convergence}

$\sigma$-convergence is based on the idea that the cross-section variation of natural gas prices decreases over time, as we would expect from series that converge. As shown in Section 3.3 the notion of pairwise convergence and that of $\sigma$-convergence are intertwined. We investigate $\sigma$-convergence for different groups of countries. We aggregate countries relying of three criteria: the existence of a trading hub, its maturity and the transmission capacity in 2017, their currency in 2017, whether they are interconnected or not and the existence of a Liquefied Natural Gas (LNG) regassification facility. Countries with LNG facilities were identified with circles in Fig. 1. The list of countries belonging to each group and its definition is provided in Appendix A.1.

Fig. 4 shows that the cross-section standard deviations tend to decrease over time, which supports the existence of $\sigma$-convergence. Moreover, in most cases a more developed wholesale gas market is associated with a lower standard deviation. As of 2017 the standard deviation of prices is lower in countries with a mature gas hub, or with LNG facilities, or share the Euro as common currency. When assessing $\sigma$-convergence we are not interested only in the level of the standard deviation, but also in the slope of the trends that in Fig. 4 are used to approximate their dynamics. Steeper negative trends are associated with countries that have high transmission capacity, share a common currency, have trading hubs or operate LNG terminals.

Table 5 provides statistical tests supporting these qualitative results. These tests are based on OLS estimation of the following model: $\hat{\sigma}_{(g) t}=\alpha_{g}+\beta_{g}$ trend $+u_{(g) t}$ where $g$ denotes a given set of countries and $u_{(g) t}$ is the error term of the regression. The third column of Table 5 highlights that countries with trading hubs, LNG facilities and high transmission capacity feature the steepest negative trend slopes. Moreover, columns 4-7 report statistical tests for the null hypothesis of "no $\sigma$-convergence" $\left(H_{0}: \beta_{g} \geq 0\right)$ against the alternative hypothesis of " $\sigma$-convergence" $\left(H_{1}: \beta_{g}<0\right)$. Although the t-statistic in the fourth column is based on heteroskedasticity and autocorrelation consistent standard errors, when $u_{(g) t}$ has strong serial correlation, or a unit root, the test tends to over-reject the null 

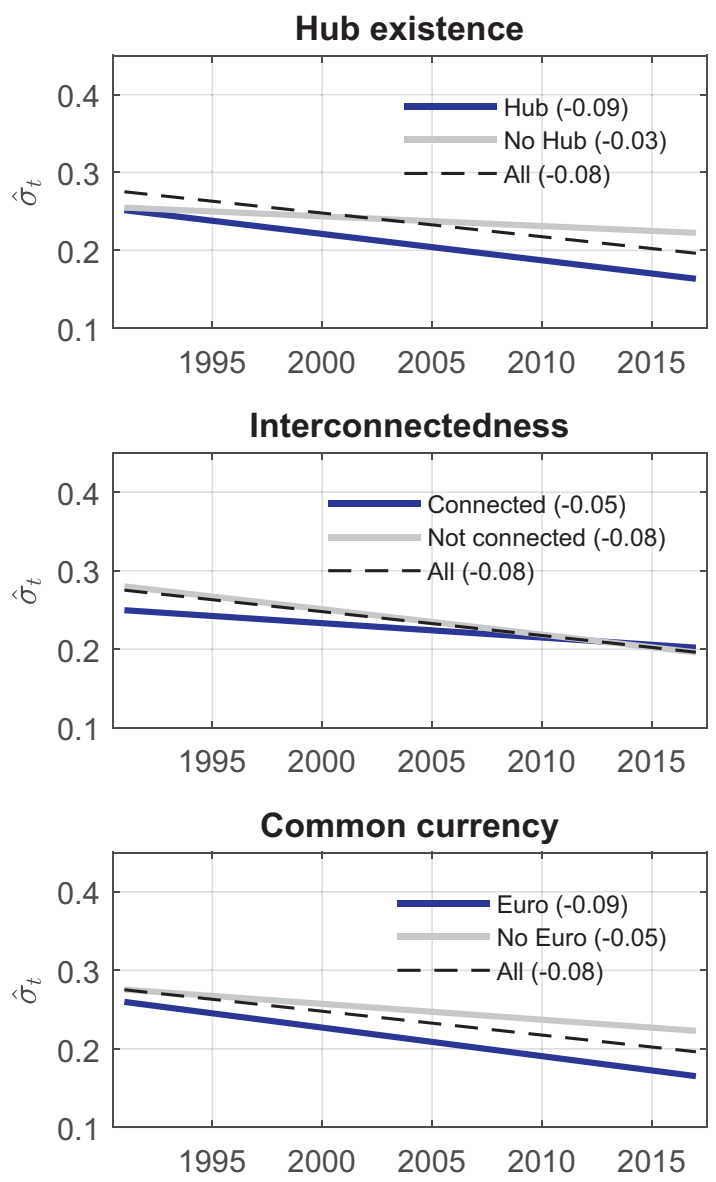
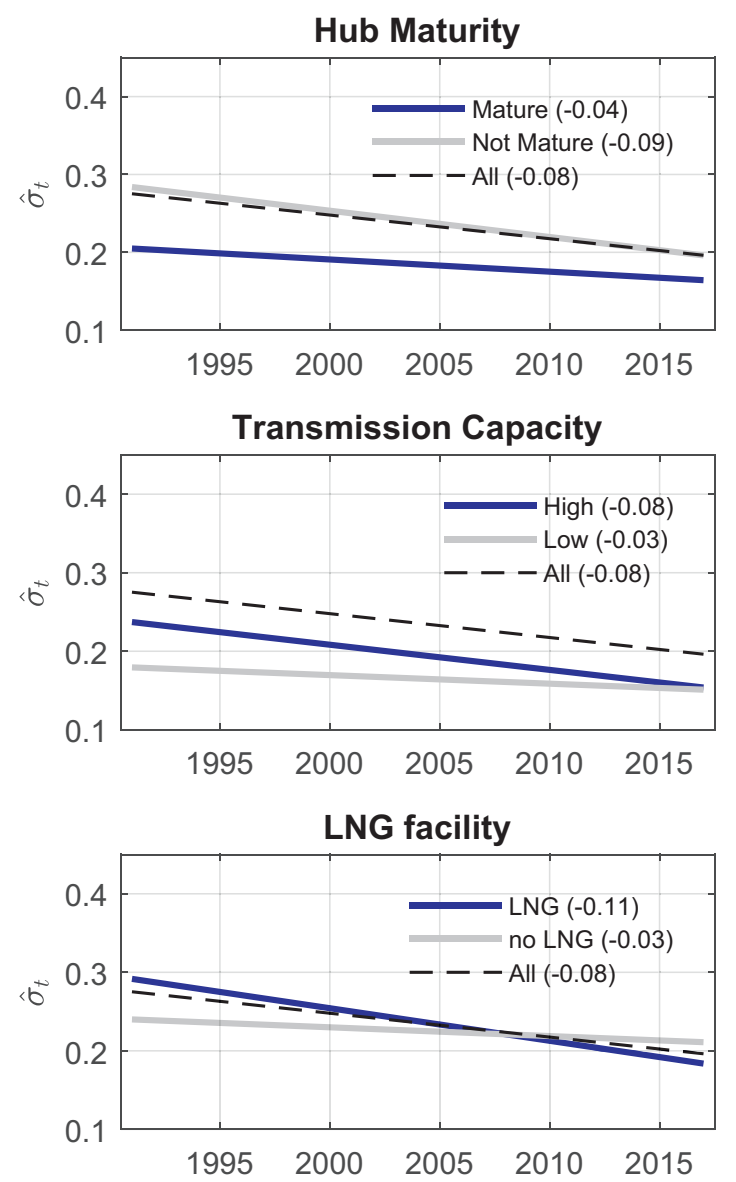

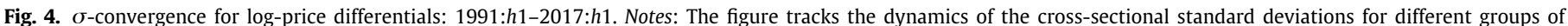

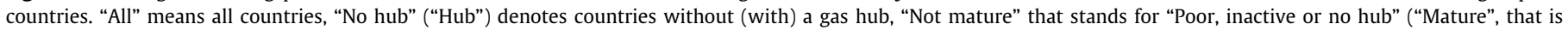

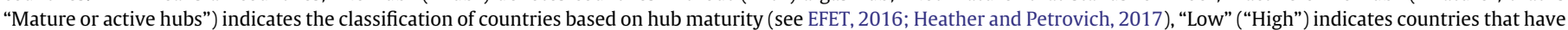

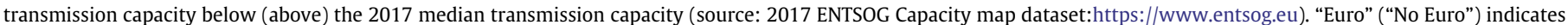

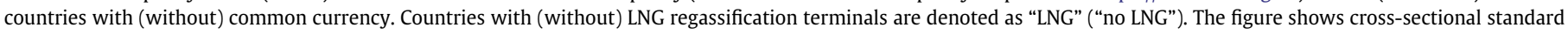
deviations fitted with a linear time trend. The numerical value in the legend is the estimated trend slope.

(Bunzel and Vogelsang, 2005). For this reason, in columns 5-7 we also present the "Dan-J" statistic due to Bunzel and Vogelsang (2005) that includes an adjustment factor to control for the over-rejection problem. ${ }^{10}$

Independently of the test being used, the null of "no $\sigma$ convergence" cannot be rejected for countries with low transmission capacity, without trading hubs or without LNG facilities. To further investigate whether the trend slope differs between countries in different groups, the last column of Table 5 proposes a test of the null hypothesis of common trend slopes. ${ }^{11}$ Overall, we confirm the qualitative evidence in Fig. 4: not only countries with trading hubs, LNG facilities and high transmission capacity are associated with the steepest negative slope, but for these countries estimated trends are statistically different from those for the complementary group of countries. For instance, focusing on the existence of a trading hub,

10 The "Dan-J" test can be written as follows: $t_{\text {Dan }}=\left[\frac{\hat{\beta}-\beta}{\operatorname{se}(\hat{\beta})}\right] \exp (-b J)$ where $s e(\hat{\beta})$ are heteroskedasticity and autocorrelation consistent standard errors based on the Daniell kernel, $b$ is a pre-specified constant that depends on the significance level of the test and $\exp (-b J)$ is a correction factor used to take into account that $u_{(g) t}$ might have strong serial correlation or a unit root. See Bunzel and Vogelsang (2005) for details.

11 This test is implemented estimating a bivariate Seemingly Unrelated Regression model where the cross-section standard deviations of two groups of countries are regressed on a trend and an intercept. we can see from columns 4-7 that there is evidence of a statistically significant $\sigma$-convergence pattern only for countries with a trading hub. In fact, for countries without a trading hub we cannot reject the null of no $\sigma$-convergence. Moreover, the last column of the table shows that these two groups of countries do not have a common trend slope. Interestingly, when analyzing countries with and without a common currency, we discover that, while there is evidence of statistically significant negative trend slope only for countries where the Euro is the common currency, the null of a common trend slope cannot be rejected. This fact, might suggest that $\sigma$-convergence is chiefly affected by gas market characteristics, rather than by other macroeconomic factors, such as the existence of common monetary policy.

\subsection{Relative convergence}

To implement the test of relative convergence à la Phillips and Sul (2007) introduced in Section 3.4 we first use the Hodrick-Prescott filter to smooth out business cycle components from the log-price series (see notes to Fig. 2 for details on filtering). OLS estimation of Eq. (10) yields $\hat{\lambda}_{1}=0.462$, with a corresponding standard error of 0.097 . This implies that the t-statistic is equal to 4.750 which is greater than the one-sided critical values at any standard level of significance: therefore, we cannot reject the null hypothesis of relative convergence. Moreover, since $0 \leq \hat{\lambda}_{1}<2$, there is evidence 
Table 5

$\sigma$-convergence for different groups of countries - 1991: $h 1-2017: h 1$.

\begin{tabular}{|c|c|c|c|c|c|c|c|}
\hline \multirow{3}{*}{$\frac{(1)}{g}$} & \multirow[b]{2}{*}{ (2) } & \multirow[b]{2}{*}{ (3) } & \multirow[b]{2}{*}{$(4)$} & \multicolumn{3}{|l|}{ Dan-J stat } & \multirow[b]{2}{*}{$(8)$} \\
\hline & & & & $(5)$ & (6) & (7) & \\
\hline & Group & $\hat{\beta}_{g}$ & t-stat & $10 \%$ & $5 \%$ & $1 \%$ & $\beta_{g}=\beta_{g+1}$ \\
\hline 0 & All & -0.079 & $-3.987^{* * *}$ & $-2.418^{c}$ & $-2.125^{b}$ & -1.405 & - \\
\hline 1 & Hub & -0.088 & $-5.469^{* * *}$ & $-2.962^{c}$ & $-2.619^{b}$ & -1.765 & 0.0167 \\
\hline 2 & No hub & -0.032 & -0.789 & -0.597 & -0.494 & -0.274 & - \\
\hline 3 & Mature or active hubs & -0.041 & $-1.959^{* *}$ & -1.318 & -1.197 & -0.880 & 0.0239 \\
\hline 4 & Poor, inactive or no hub & -0.088 & $-4.157^{* * *}$ & $-2.549^{c}$ & $-2.222^{b}$ & -1.432 & - \\
\hline 5 & Connected & -0.048 & $-2.360^{* *}$ & -0.980 & -0.739 & -0.300 & 0.0387 \\
\hline 6 & Not onnected & -0.084 & $-3.620^{* * *}$ & $-2.258^{c}$ & $-1.956^{b}$ & -1.237 & - \\
\hline 7 & Euro & -0.095 & $-4.526^{* * *}$ & $-3.182^{c}$ & $-2.797^{b}$ & -1.853 & 0.2175 \\
\hline 8 & No Euro & -0.053 & -1.233 & -0.796 & -0.656 & -0.355 & - \\
\hline 9 & High transmission capacity & -0.083 & $-4.324^{* * *}$ & $-2.312^{c}$ & $-2.017^{b}$ & -1.304 & 0.0444 \\
\hline 10 & Low transmission capacity & -0.028 & -1.119 & -0.679 & -0.551 & -0.281 & - \\
\hline 11 & LNG facility & -0.108 & $-5.084^{* * *}$ & $-2.891^{c}$ & $-2.453^{b}$ & -1.450 & 0.0000 \\
\hline 12 & No LNG facility & -0.029 & -1.262 & -0.811 & -0.705 & -0.450 & - \\
\hline
\end{tabular}

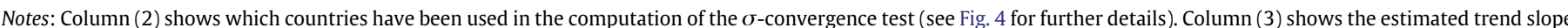

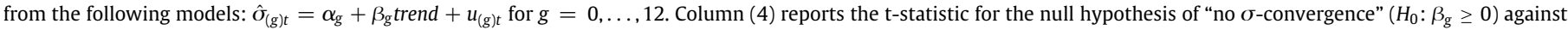

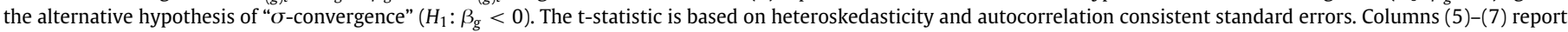

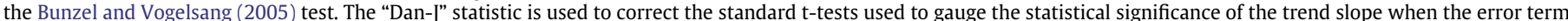

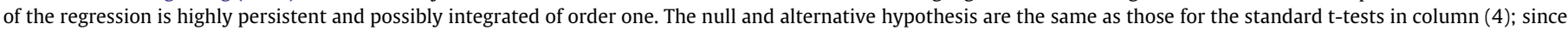

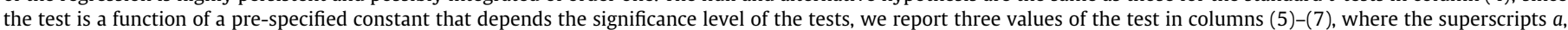

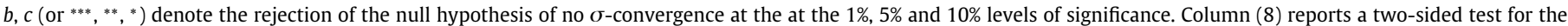

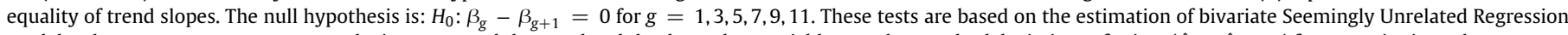

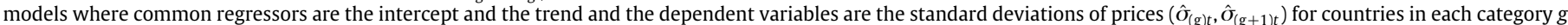
for $g=1,3,5,7,9,11$ (e.g. countries with and without a trading hub).

that European gas prices feature growth rate convergence, but not log-level convergence.

\section{Robustness checks and further results}

\subsection{Different price series}

As detailed in Section 2.1 all results in the paper are based on before tax (BT) nominal (N) prices paid by medium-sized industrial consumers. We now check the robustness of results with respect to this sample design. More precisely, we consider the following alternative price series: (i) BT real (R) prices; (ii) BT/N prices based on a different strategy to handle the change in Eurostat's methodology in 2007, (iii) BT/N prices starting in 1996, (iv) after tax nominal prices (AT/N). Below we briefly comment the main findings as summarized in Table 6 , while to save space tables with detailed results appear Section A.4.4 of Appendix A.

\subsubsection{Before tax real prices}

We have constructed real natural gas prices relying on quarterly Consumer Price Indices (CPIs) sourced from the International Financial Statistics maintained by the International Monetary Fund. Half-yearly CPIs are computed as sample averages of quarterly CPIs (e.g. the CPI for the first semester equals the sample average of the CPI in the first and second quarter of the year). Real prices - expressed in 2017 Euro - are then computed as: $R P_{i, t}=P_{i, t} \times C P I_{i, t} / C P I_{i, 2017: h 1}$, where $P_{i, t}$ is the BT price of natural gas for industrial consumers in country $i$. Table 6 shows that, as for pairwise convergence, the fraction of rejections of the null hypothesis of a unit root in the price differential for $\mathrm{BT} / \mathrm{R}$ is lower than for $\mathrm{BT} / \mathrm{N}$, but is still $4-5$ times higher than the nominal size of the test. Similarly, we can confirm that real prices display $\sigma$-convergence and that the Phillips-Sul test provides empirical evidence in favor of relative convergence. Interestingly, since $\hat{\lambda}_{1} \approx 2$ for BT/R prices the Phillips-Sul methodology suggests that there is evidence of log-level convergence.

Table 6

Robustness with respect the price series.

\begin{tabular}{|c|c|c|c|c|c|c|c|}
\hline \multirow[b]{4}{*}{ Price } & \multicolumn{3}{|c|}{ Pairwise convergence } & & & & \\
\hline & \multicolumn{3}{|l|}{ DF-GLS test } & & & & \\
\hline & \multicolumn{3}{|l|}{$10 \%$} & & & & \\
\hline & & SIC & $\% t$ & \multicolumn{2}{|c|}{$\sigma$-convergence } & \multicolumn{2}{|c|}{ Relative conv. } \\
\hline \multirow[t]{2}{*}{$\mathrm{BT} / \mathrm{N}$} & Const & 69.2 & 38.1 & $\hat{\beta}_{g}$ & -0.079 & $\hat{\lambda}_{1}$ & 0.462 \\
\hline & Const/trend & 64.8 & 40.7 & t-stat & $-3.987^{* * *}$ & t-stat & 4.570 \\
\hline \multirow[t]{2}{*}{$\mathrm{BT} / \mathrm{R}$} & Const & 39.6 & 41.7 & $\hat{\beta}_{g}$ & -0.605 & $\hat{\lambda}_{1}$ & 1.953 \\
\hline & Const/trend & 49.5 & 33.3 & t-stat & $-7.925^{* * *}$ & t-stat & 17.645 \\
\hline \multirow[t]{2}{*}{ BT/N - backcast } & Const & 62.6 & 40.4 & $\hat{\beta}_{g}$ & -0.106 & $\hat{\lambda}_{1}$ & 0.838 \\
\hline & Const/trend & 58.2 & 43.4 & t-stat & $-4.349 * * *$ & t-stat & 6.043 \\
\hline \multirow[t]{2}{*}{ BT/N from 1996} & Const & 61.5 & 50.0 & $\hat{\beta}_{g}$ & -0.071 & $\hat{\lambda}_{1}$ & -0.030 \\
\hline & Const/trend & 72.5 & 42.4 & t-stat & $-2.937^{* * *}$ & t-stat & -0.772 \\
\hline \multirow[t]{2}{*}{$\mathrm{AT} / \mathrm{N}$} & const & 42.9 & 30.8 & $\hat{\beta}_{g}$ & 0.091 & $\hat{\lambda}_{1}$ & -0.556 \\
\hline & const/trend & 54.9 & 24.0 & t-stat & 3.596 & t-stat & $-94.797^{* * *}$ \\
\hline
\end{tabular}

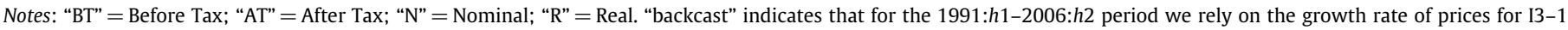

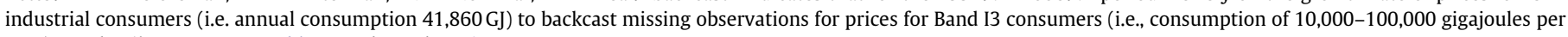
year). For details see notes to Tables 2 and 5 and Section 4.3. 


\subsubsection{Before tax nominal prices - backcast}

As detailed in Section 4.1.1 in 2007 Eurostat introduced a new methodology to collect natural gas price data. Starting from that year "consumption bands" have replaced "consumers standards". Our main results are based on $\mathrm{BT} / \mathrm{N}$ prices for $\mathrm{I} 3-1$ industrial consumers for the 1991:h1-2006: $h 2$ period and on prices for Band I3 consumers from 2007: $h 1$ onwards. To check whether this choice affects our results, we now consider a different strategy to handle the change in Eurostat's data collection procedures. More precisely, for the 1991:h1-2006:h2 period we rely on the growth rate of BT prices for I3-1 industrial consumers to backcast $\mathrm{BT} / \mathrm{N}$ prices for Band $\mathrm{I} 3$ consumers that are available only from 2007 onwards. Considering these alternative price series we see from the rows of Table 6 labeled as "BT/N - backcast" that all our main results are confirmed. There is evidence of pairwise and $\sigma$ convergence. Moreover, the Phillips-Sul procedure yields $\hat{\lambda}_{1}=0.84$ and hence confirms that European gas prices feature growth rate convergence, but not log-level convergence.

\subsubsection{Before tax nominal prices starting in 1996}

As shown in Fig. 3 the ETCR index for natural gas started following a decreasing trend only during the mid-1990s. This is consistent with the fact that until the mid-1990s most European national electricity and natural gas markets were still monopolized. The first liberalization directives were adopted in 1996 for electricity and in 1998 for gas in the context of the "First Energy Package". ${ }^{12}$ For this reason we have also considered convergence analysis on a sample of BT nominal prices starting in 1996. While restricting the sample to the most recent period allows us to focus on more informative prices, the reduction of sample size also impacts on the statistical procedures lowering the efficiency of estimators and reducing the power of unit root tests. As we can see from the rows of Table 6 labeled as "BT/N from 1996", results based on this shorter sample are qualitatively similar to our main findings.

\subsubsection{After tax nominal prices}

$\mathrm{BT} / \mathrm{N}$ prices were used both to avoid that fiscal policy could represent a confounding factor for the convergence analysis and to be consistent with the earlier literature (see e.g., Robinson, 2007; Renou-Maissant, 2012). Nevertheless, since after tax (AT) nominal prices represent what consumers actually pay, it is interesting to analyze whether convergence in $\mathrm{BT} / \mathrm{N}$ prices carries over to $\mathrm{AT} / \mathrm{N}$ prices. We have sourced these data from Eurostat and we have constructed time series of $\mathrm{AT} / \mathrm{N}$ prices for medium-sized consumers with the same approach detailed in Section 2.1 for BT/N prices. As expected, the heterogeneity in European fiscal policies does affect our empirical results. The last two rows of Table 6 show that $\sigma$ - and relative convergence are not supported by the data when relying on $\mathrm{AT} / \mathrm{N}$ prices. As for pairwise convergence, we observe a reduction in the fraction of stationary price differentials.

\subsection{Persistence profiles}

While the notion of convergence has to do with the long-run behavior of prices, it is useful to provide policy makers with evidence about its short-run implications. This can be achieved focusing on the speed with which prices return to equilibrium after a shock.

To that end, we estimate persistence profiles (PPs) of log-prices for each pair of countries. ${ }^{13}$ PPs, popularized by Lee and Pesaran (1993) and Pesaran and Shin (1996), allow to trace the effect of a shock to one or more cointegrating relations through time. In the case of two series that have a unit root, but are not cointegrated the $\mathrm{PP}$ would never converge to zero, while in the case of cointegrated

\footnotetext{
12 See http://www.europarl.europa.eu/factsheets.

13 We thank Lutz Kilian who suggested this methodology to us.
}

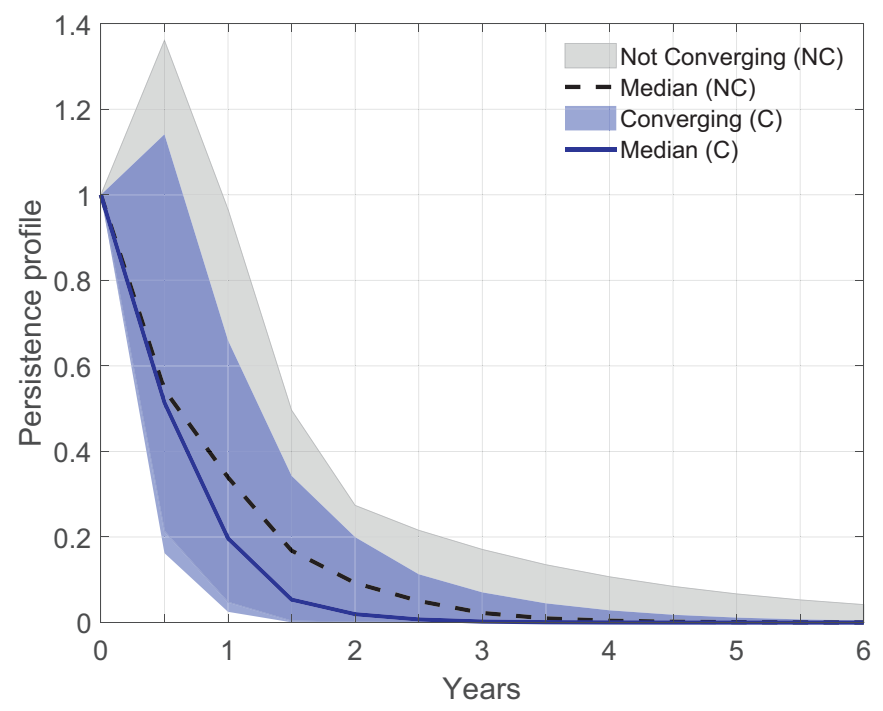

Fig. 5. Persistence profiles: 1991:h1-2017:h1. Notes: The figure shows the persistence profiles estimated using a bivariate Vector Error Correction Models (VECM) of order 1 for each log-price pair. The figure distinguishes pairs for which there is evidence of pairwise convergence from those that do not display a converging behavior. In both cases we report the whole distribution of persistence profiles and their median. A pair of log-prices is converging if the null hypothesis of unit root is rejected based on the DF-GLS test of Elliott et al. (1996) at the 10\%. For further details see notes to Table 2.

log-prices the effect of a shock is transitory and would eventually die out. To assess the impact of price convergence on the speed of adjustment to equilibrium, we aggregate PPs into two groups: those for country pairs with and without converging natural gas prices. Here, a pair of log-prices is defined as "converging" if the null hypothesis of unit root is rejected based on the DF-GLS test of Elliott et al. (1996) at the $10 \%$ (i.e. bottom line of column 7 in Panel (b) of Table 2; further details are provided in Appendix A.5).

Fig. 5 shows estimated PPs for all pairs of converging and nonconverging log-prices. Two shaded areas are plotted, one for each group of prices; these bands are bounded by the maximum and the minimum PPs and contain the median PP for the group. As we can see the effects of shocks are scaled to have a unit effect on impact. Moreover, we can see that while both bands shrink toward zero, PPs for converging country pairs tend to do so much earlier. More precisely, while for converging pairs after four years there is basically no more sign of the shock, for non-converging countries PPs are still bounded between zero and 0.1 , meaning that, for some prices $10 \%$ of the shock has yet to disappear. Focusing on a shorter horizon and looking at the median PP, we see that after a year $80.3 \%$ of the adjustment process for converging pairs has already been completed. This percentage is only $66.1 \%$ for non-converging prices. All in all, PPs in Fig. 5 convey a very clear message: long-run price convergence helps to restore equilibrium in natural gas markets and this has short-run policy implications. In fact, the speed of adjustment ultimately affects the welfare of citizens that have to pay higher bills for a longer time period. If, say, a supply-side oil price shock originating in a producing country hits the global economy and natural gas contracts are linked to the price of crude oil, in countries with converging prices its effects will die out earlier.

\section{Discussion and conclusions}

This paper has investigated the convergence of natural gas prices in fourteen European countries. We have focused on prices paid by "medium-sized" industrial consumers over the period 1991-2017. 
Our empirical analysis was based on the notion of pairwise convergence that requires less restrictive hypotheses than other convergence concepts used in the literature. In addition, the chosen methodology does not require to select a benchmark price and can be applied to samples of any dimension. On the contrary, methods based on cointegration tests are not well suited in settings where the cross-sectional dimension is large.

Our results show that there is evidence of pairwise, $\sigma$ - and relative price convergence and that this process is associated with key characteristics of the gas market, such as the existence of trading hubs, as well as the degree of interconnection. This result is robust to a number of changes in the implementation of the tests.

Price convergence across European gas markets is thus more likely to occur when each national gas system delivers reliable signals of its state, a feature that comes together with the establishment and maturity of gas hubs. Moreover, sufficient interconnection among national gas systems is needed, requiring to remove physical and contractual barriers to trade and arbitrage. In a perfectly interconnected European system the cross-countries arbitrage opportunities would be easily exploited by operators, pushing toward a single European price. Hence, the relevant issue refers to which frictions may prevent such super-national adjustment to take place.

Firstly, there is an issue of physical transmission capacity across countries, that may limit the ability to trade across markets and maintain price differentials. In other words, fluid cross-country gas trade is not possible without sufficient transmission capacity. These frictions are more frequently temporary ones, due to large supply or demand shocks that would require a cross-country trade larger than transmission capacity. This occurred, for instance, in September 2016 when the interconnector between the UK and Belgium broke down, or recurrently in the interconnection between the Austrian and the German systems during the summer. The physical issue calls for infrastructural projects to increase the capacity and remove the bottlenecks.

Secondly, since transmission capacity is ruled by contracts, these latter may become another source of frictions that prevent crosscountry arbitrage and price alignments. This is the case with the connection of the Italian system with the north-west European area through the Transitgas pipelines, although a reform in the congestion management procedures improved the performance from the second half of 2016. Similar issues arise in the Spanish and Polish markets. Contractual issues require a regulatory intervention to remove restrictive clauses and promote an efficient congestion management. We can notice that if interconnection is extremely efficient, even small and not very liquid national gas hubs may deliver converging prices taking advantage of the large liquidity of the gas systems they are interconnected with. The example of the infant Czech hub very well interconnected with the north-west area of the Dutch and German systems is a good example of this "substitution potential" between internal liquidity and international interconnection.

\section{Acknowledgments}

This paper was part of IEFE-Bocconi research program on "Energy Markets and Other Network Industries". We thank for their comments participants to the 1st Paris International Conference on the Economics of Natural Gas held in June 2017 and to the 6th International Symposium on Environment and Energy Finance Issues held in Paris in May 2018. We also acknowledge the comments and suggestions of two anonymous referees who helped improving this paper.

\section{Appendix A}

A.1. Country groupings

Table A1

Groups of countries.

(a) Common currency
- Euro: Austria, Belgium, Germany, Spain, France, Ireland, Italy, Luxembourg, Netherlands, Slovenia

(b) Natural gas hub

- Countries with a trading hub: Austria, Belgium, Germany, Denmark, Spain, France, Hungary, Ireland, Italy, Netherlands, United Kingdom

- Mature or active hubs: Belgium, Germany, France, Italy, Netherlands, United Kingdom

- Poor, inactive or no hubs: Austria, Denmark, Spain, Hungary, Ireland, Luxembourg, Sweden, Slovenia

(c) Transmission capacity

- High: Austria, Belgium, Germany, Spain, France, Netherlands, United Kingdom

- Low: Denmark, Hungary, Ireland, Italy, Luxembourg, Sweden, Slovenia

(d) No. of interconnections

- 1 interconnection: Spain, Hungary, Ireland, Sweden

- 2 interconnections: Denmark, Italy, Luxembourg, Slovenia

$\bullet \geq 3$ interconnections: Austria, Belgium, Germany, France, Netherlands

(e) LNG regassification facility

- Countries with LNG terminals: Belgium, Spain, France, Italy, Netherlands, United Kingdom

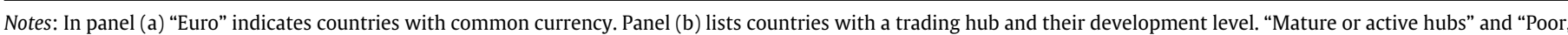

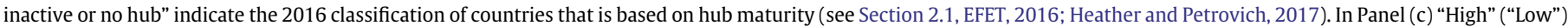

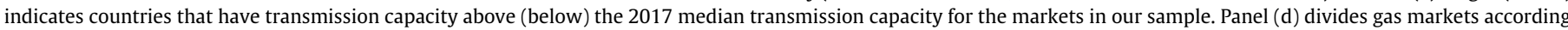

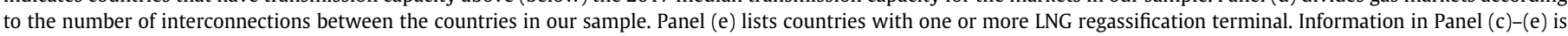
based on: the 2017 ENTSOG Capacity map dataset:https://www.entsog.eu. 


\section{A.2. Natural gas markets and technical physical capacity}

Fig. A1 displays an undirected and a directed network graph of the natural gas markets we are studying. ${ }^{14}$ In these graphs the size of nodes is proportional to the country's technical physical capacity, given by the total of within EU inflows and outflows, export to non-EU countries and technical physical capacity at LNG terminals. In panel (a) the thickness of the edges connecting the nodes is proportional to the technical physical capacity between two countries, while the arrows in panel (b) indicate the direction of the gas flow. It is important to note that we consider only the capacity of the interconnections between the countries in our sample.

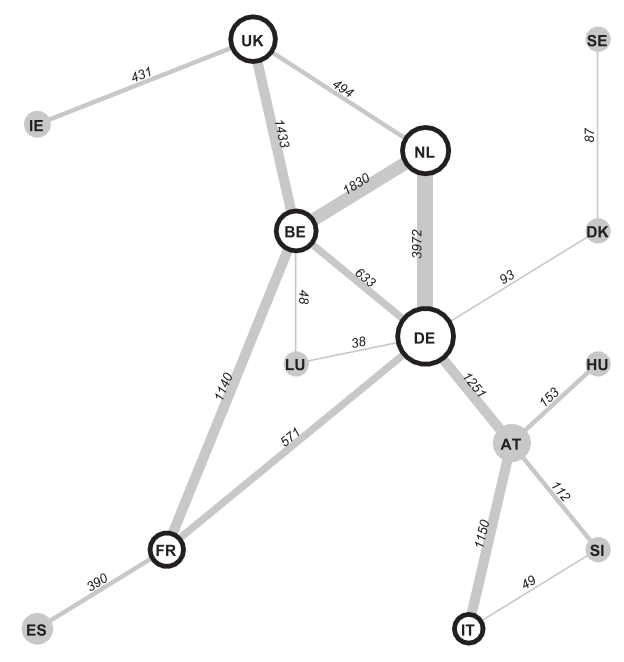

(a) Undirected graph

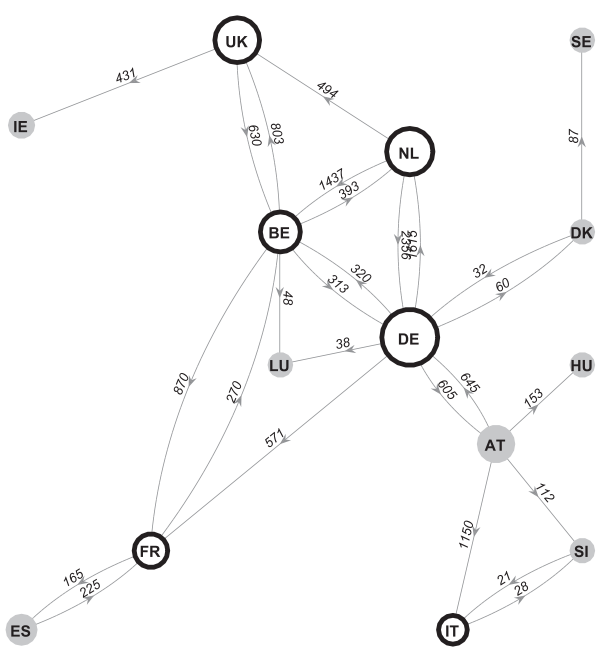

(b) Directed graph

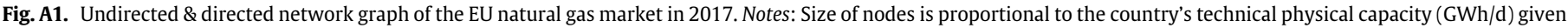

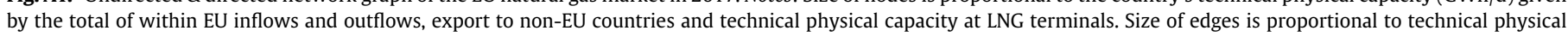

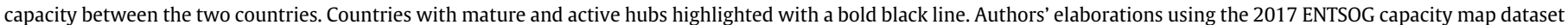
(https://www.entsog.eu).

\section{A.3. The OECD ETCR database}

The OECD indicators of regulation in energy, transport, and communications (ETCR) collect survey information about regulatory structures and policies for OECD and some non-OECD countries (see Koske et al., 2015, for details). All answers are normalized in a range from zero to six, where values near zero indicate fewer restrictions to competition (see Bastianin et al., 2018, for a discussion of categorical proxies of reform). Data have annual sampling frequency and are available for the 1975-2013 period. As shown in Fig. A2, the ETCR index is available at different levels of aggregation. The Product Market Regulation (PMR) index in column 6 of Table 1 aggregates with equal weights the sub-indicators for seven network industries: natural gas, electricity, air, rail, road transport, post and telecommunications. For each sector, up to four dimensions of regulatory policy are analyzed: entry regulation, public ownership, vertical integration and market regulation. These sub-indexes for gas markets are shown in Table A2, while Fig. 3 in the main text shows the aggregate index for natural gas.

\footnotetext{
14 Fig. A1 relies on the 2017 ENTSOG capacity map dataset (https://www.entsog.eu).
} 


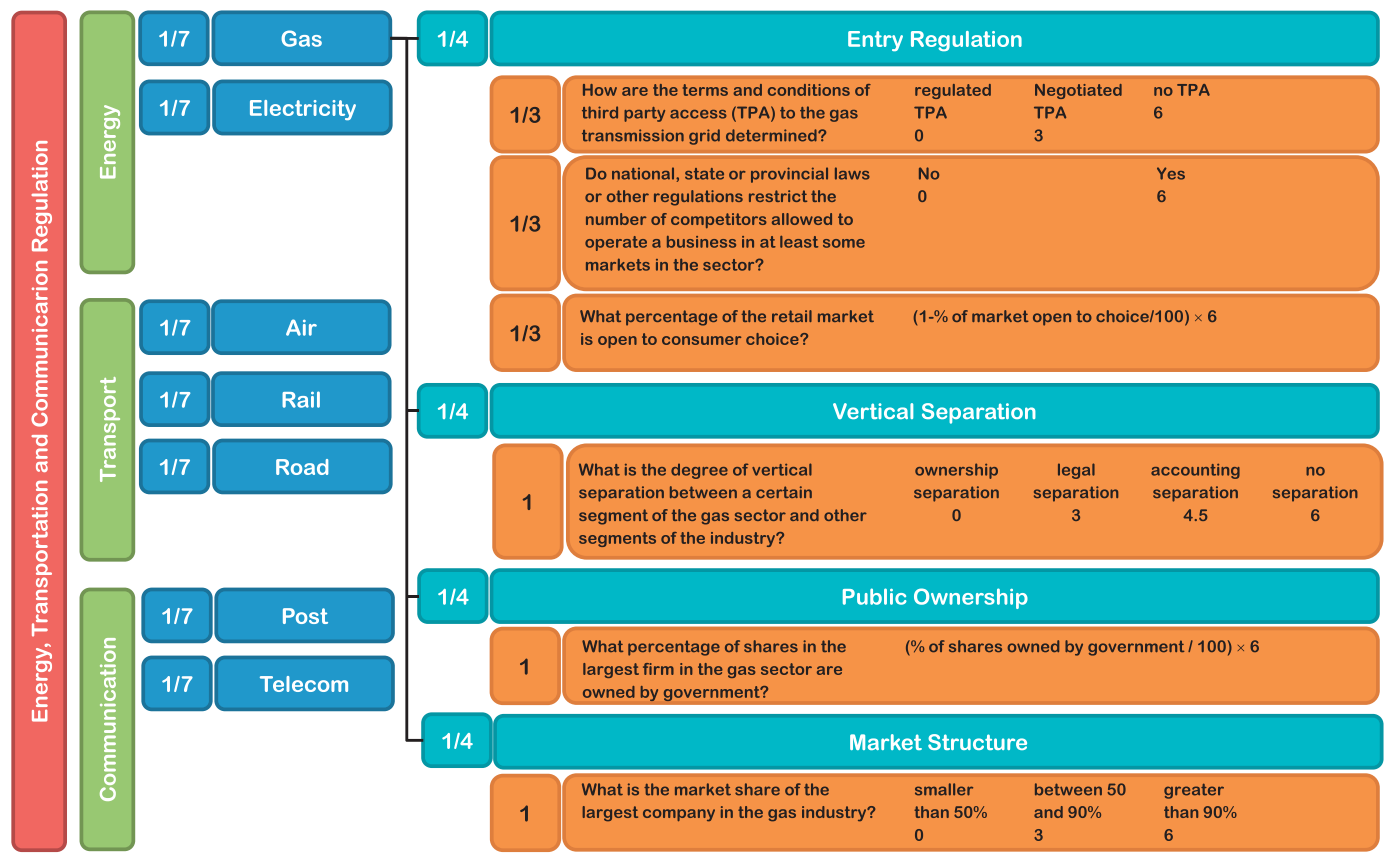

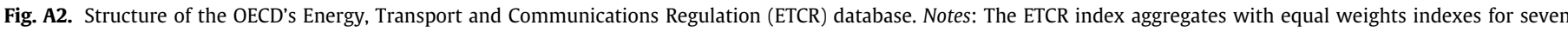

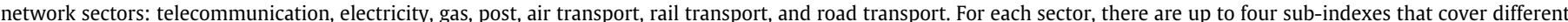

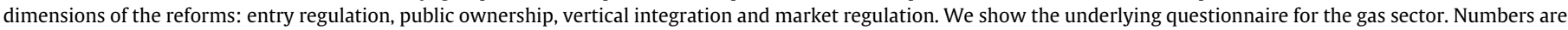
sector-, topic- and question-weights used for aggregation purposes.

Source: Source: Bastianin et al. (2018).

Table A2

Descriptive statistics for the European natural gas markets in 2013.

\begin{tabular}{|c|c|c|c|c|c|c|}
\hline \multirow[b]{2}{*}{ (1) } & \multirow[b]{2}{*}{ (2) } & \multicolumn{5}{|c|}{ ETCR score } \\
\hline & & $(3)$ & $(4)$ & $(5)$ & $(6)$ & (7) \\
\hline iso & Country & Gas & ER & PO & VI & MS \\
\hline AT & Austria & 2.2 & 0.0 & 2.8 & 4.7 & 1.5 \\
\hline $\mathrm{BE}$ & Belgium & 1.7 & 0.0 & 2.2 & 4.5 & 0.0 \\
\hline $\mathrm{DE}$ & Germany & 1.2 & 0.0 & 0.0 & 4.7 & 0.0 \\
\hline DK & Denmark & 2.6 & 0.0 & 4.5 & 4.5 & 1.5 \\
\hline ES & Spain & 1.1 & 0.0 & 0.1 & 3.0 & 1.5 \\
\hline FR & France & 2.5 & 0.0 & 2.4 & 4.7 & 3.0 \\
\hline $\mathrm{HU}$ & Hungary & 1.7 & 1.0 & 0.6 & 3.2 & 2.3 \\
\hline IE & Ireland & 3.0 & 0.0 & 5.8 & 4.5 & 1.5 \\
\hline IT & Italy & 1.9 & 0.0 & 1.8 & 4.9 & 0.8 \\
\hline LU & Luxembourg & 2.6 & 0.0 & 2.8 & 4.7 & 3.0 \\
\hline NL & Netherlands & 2.3 & 0.5 & 3.5 & 4.5 & 0.8 \\
\hline SE & Sweden & 1.7 & 0.0 & 0.0 & 3.8 & 3.0 \\
\hline SI & Slovenia & 2.8 & 0.0 & 3.3 & 4.9 & 3.0 \\
\hline UK & UK & 0.0 & 0.0 & 0.0 & 0.0 & 0.0 \\
\hline
\end{tabular}

Notes: Columns 3-7 report ETCR scores sourced from the OECD's Energy, Transport and Communications Regulation (Koske et al., 2015). These data represent a scoring system on a scale from zero to six, where values near zero indicate fewer restrictions to competition. We report an overall score for the gas market ("Gas") that is the average of the scores for entry regulation ("ER"), public ownership ("PO"), vertical separation ("VS") and market structure ("MS").

\section{A.4. Further results}

\section{A.4.1. Log-price differentials: visual inspection}

Fig. A3 displays log-prices as differences from the cross-country average (a) and log-price differentials $\left(d_{i j, t}=p_{i, t}-p_{j, t},\right)(\mathrm{b})$. Recall that pairwise convergence implies that two prices converge if $d_{i j, t}$ is stationary with constant mean. With $N=14$ countries, we have a total of $N(N-1) / 2=91 \log$-price differentials to test. Visual inspection of Fig. A3 (b) does not provide any clear evidence in support of, or against convergence. However, in countries with an active or mature trading hub (identified by darker lines) log-price differentials tend to be less dispersed. This is even more evident in Panel (a), where at the end of the sample the spread of the log-prices (in difference from the cross-country average) decreases, especially in countries where there is an active or mature trading hub. These facts qualitatively support the existence of $\sigma$-convergence, namely the tendency for price differentials to become less dispersed over time (see also Sections 4.2 and 3.3 in the main text). 


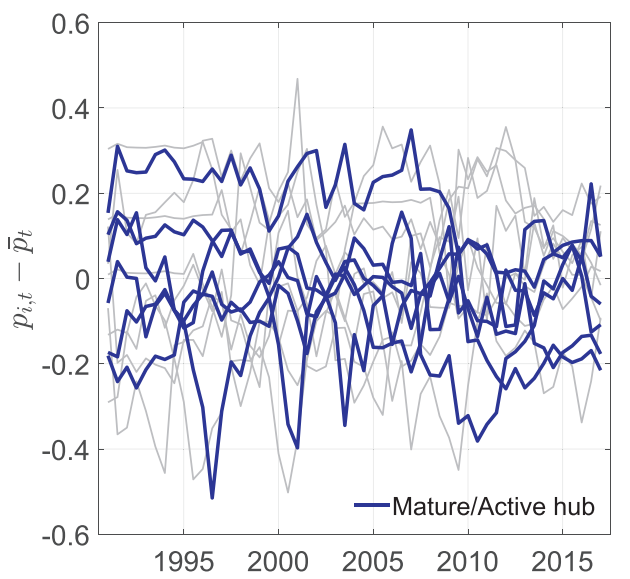

(a) Log-price: difference from cross-country sample average

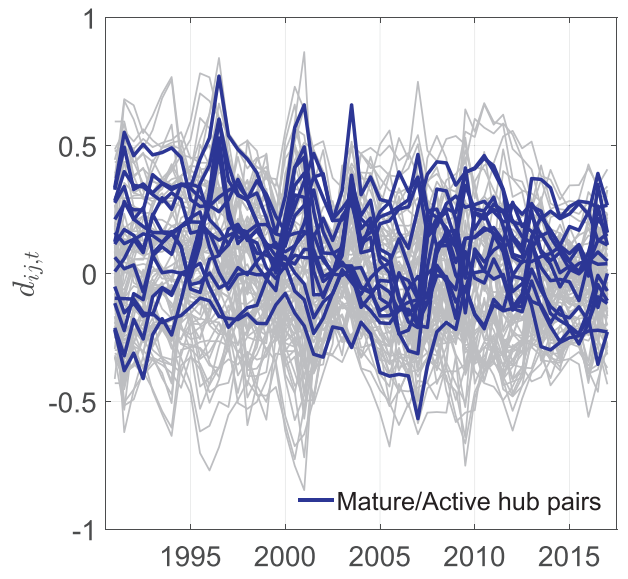

(b) Log-price differential

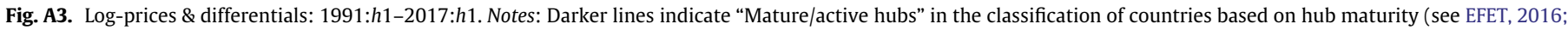
Heather and Petrovich, 2017).

Table A3

Pairwise convergence based on the Zivot and Andrews (2002) test: 1991:h1-2017:h1.

\begin{tabular}{|c|c|c|c|}
\hline (1) & (2) & (3) & $(4)$ \\
\hline Model & $5 \%$ & $10 \%$ & Break date \\
\hline Break in intercept & 39.56 & 47.25 & 2001:h2 \\
\hline Break in intercept \& trend & 37.36 & 47.25 & 2001:h2 \\
\hline
\end{tabular}

Notes: Columns (2)-(3) show the percentage of the 91 log-price differentials $\left(d_{i j, t}\right)$ for which the null hypothesis of unit root is rejected relying on the Zivot and Andrews (2002) test $\left(\bar{Z}_{N T}\right)$. The alternative hypothesis of the test is that $d_{i j, t}$ is stationary process with a break in the intercept or in the intercept and trend, see column (1). See notes to Table 2 for further details.

\section{A.4.2. Structural breaks \& sub-sample analysis: further results}

A.4.2.1. The Second Gas Directive - 2004. With the Second Gas Directive of 2003 industrial consumers were allowed to freely choose their suppliers. Since the Directive entered into force in July 2004, we split the sample in two sub-periods: 1991:h1-2004:h1 and 2004:h2-2017:h1. Table A4 shows that after 2004 the percentage of rejections of the null hypothesis exhibits a uniform increase. The share of log-price differentials that do not display statistically significant linear trends is also very high. However, also in this case we note that this percentage tends to decrease during the second period. Because of this and because there might be confounding factors we are not controlling for, we cannot draw conclusions on the causality between liberalizations and convergence.

Table A4

Pairwise convergence tests - before \& after the Second Gas Directive.

\begin{tabular}{|c|c|c|c|c|c|c|c|}
\hline \multicolumn{4}{|l|}{$5 \%$} & \multicolumn{4}{|l|}{$10 \%$} \\
\hline (1) & (2) & (3) & (4) & (5) & (6) & (7) & (8) \\
\hline AIC & $\% t$ & SIC & $\% t$ & AIC & $\% t$ & SIC & $\% t$ \\
\hline \multicolumn{8}{|l|}{ 04:h1 } \\
\hline 24.2 & 90.9 & 20.9 & 84.2 & 33.0 & 70.0 & 34.1 & 77.4 \\
\hline 29.7 & 74.1 & 23.1 & 76.2 & 34.1 & 67.7 & 36.3 & 72.7 \\
\hline
\end{tabular}

(a) ADF test: 1991:h1-2004:h1

Const 24.2

Const/trend $\quad 29.7$

$74.1 \quad 23.1$

76.2

67.7

77.4

(b) ADF test: 2004:h2-2017:h1

Const 25.3

Const/trend $\quad 34.1$

69.6

23.1

30.8

61.9

36.3

$\begin{array}{ll}46.4 & 39.6\end{array}$

54.5

50.0

31.9

38.5

(c) DF-GLS test: 1991:h1-2004:h1

Const

23.1

71.4

31.9

79.3

61.3

44.0

Const/trend

23.1

29.7

85.2

34.1

59.4

(d) DF-GLS test: 2004:h2-2017:h1

Const $\quad 38.5$

38.5
39.6

54.3

Const/trend

52.8

30.8

36.3

53.6

(e) ADF-WS test: 1991:h1-2004:h1

Const

31.9

Const/trend

24.2

$65.5 \quad 31.9$

$\begin{array}{ll}53.6 & 50.5 \\ 45.5 & 53.8\end{array}$

56.5

$56.5 \quad 42.9$

50.5

56.4

53.8

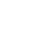

24.2

65.5

31.9

65.5

67.9 


\begin{tabular}{|c|c|c|c|c|c|c|c|c|}
\hline & \multicolumn{4}{|l|}{$5 \%$} & \multicolumn{4}{|l|}{$10 \%$} \\
\hline & $(1)$ & $(2)$ & (3) & $(4)$ & $(5)$ & $(6)$ & $(7)$ & $(8)$ \\
\hline & AIC & $\% t$ & SIC & $\% t$ & AIC & $\% t$ & SIC & $\% t$ \\
\hline \multicolumn{9}{|c|}{ (f) ADF-WS test: 2004:h2-2017:h1 } \\
\hline Const & 50.5 & 56.5 & 50.5 & 56.5 & 50.5 & 56.5 & 50.5 & 56.5 \\
\hline Const/trend & 46.2 & 61.9 & 46.2 & 61.9 & 53.8 & 53.1 & 53.8 & 53.1 \\
\hline
\end{tabular}

Notes: The maximum lag order is set equal to 2 that corresponds to one year; for further details see notes to Table 2 .

A.4.2.2. The KSS test. An alternative way of controlling for possible structural breaks in the analysis of pairwise convergence is to consider the test of Kapetanios et al. (2003) (KSS, henceforth). These authors developed a test for the null hypothesis of a unit root that has power against the alternative that the log-price differential is generated by a smooth transition autoregressive model. Pesaran et al. (2009) pointed out that the KSS test has also power against a three-regime threshold alternative. This feature of the KSS test is relevant for our analysis that is based on a relatively small sample, thus preventing us from using unit root tests that allow to accommodate more than one structural break. Results in Table A5 show that our results are robust also when considering this test. In particular, the percentage of rejections of the null hypothesis of a unit root are similar to those reported in Table 2 . The same applies to the share of log-price differentials that do not display statistically significant linear trends.

Table A5

Pairwise convergence based on the Kapetanios et al. (2003) test - 1991:h1-2017:h1.

\begin{tabular}{|c|c|c|c|c|c|c|c|c|}
\hline & \multicolumn{4}{|l|}{$5 \%$} & \multicolumn{4}{|l|}{$10 \%$} \\
\hline & (1) & $(2)$ & (3) & $(4)$ & (5) & (6) & (7) & $(8)$ \\
\hline & AIC & $\% t$ & SIC & $\% t$ & AIC & $\% t$ & SIC & $\% t$ \\
\hline Const & 40.7 & 35.1 & 39.6 & 38.9 & 52.7 & 33.3 & 47.3 & 34.9 \\
\hline Const/trend & 46.2 & 31.0 & 42.9 & 35.9 & 56.0 & 31.4 & 49.5 & 33.3 \\
\hline
\end{tabular}

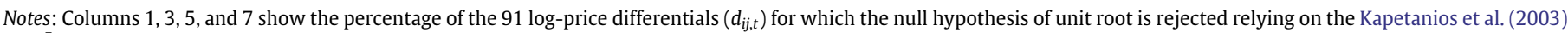

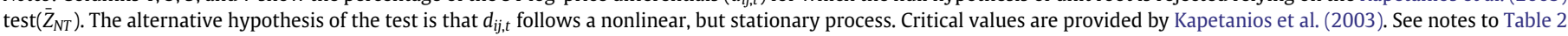
for further details.

\section{A.4.3. Pairwise convergence tests for different country groups}

We now turn to the analysis of pairwise convergence across different country groups. We aggregate countries relying of three criteria: the existence of a trading hub, its maturity and the transmission capacity in 2017 . The list of countries belonging to each group and its definition is provided in Appendix A.1.

Table A6 shows that the existence of a trading hub is associated with a small increase in the fraction of rejections of the null hypothesis of a unit root in the log-price differentials. Also the degree of development of the trading hub is associated with an increase in the share of country pairs for which there is evidence of pairwise convergence. Lastly, we group countries using their transmission capacity in 2017. The rows headed "Low transmission capacity" and "High transmission capacity" identify countries that have transmission capacity below or above the median of the sample for 2017 (Source: ENTSOG Capacity Map for 2017). In countries with high transmission capacity the frequency of country pairs for which the log-price differential does not feature a unit root is higher than for country pairs with capacity below the 2017 median.

All in all, the existence of pairwise convergence seems to be positively associated with the developments of wholesale gas markets and the degree of interconnection. Empirical evidence in support of pairwise convergence is sharper for countries with high transmission capacity and well-functioning trading hubs. Of the three characteristics we have investigated, the degree of development of the trading hub seems to be the most important; in fact, for these country pairs the share of rejections of the null of a unit root in the log-price differential increases by about $10 \%$ compared with the result for the entire set of country pairs.

Table A6

Pairwise convergence for different country groups - 1991:h1-2017:h1.

\begin{tabular}{|c|c|c|}
\hline \multirow[t]{2}{*}{ (1) } & $(2)$ & (3) \\
\hline & $\bar{Z}_{N T}$ & $\% t$ \\
\hline All & 64.8 & 40.7 \\
\hline No hub & 63.9 & 52.2 \\
\hline Hub & 65.5 & 33.3 \\
\hline Poor, inactive or no hubs & 63.2 & 41.7 \\
\hline Mature or active hubs & 73.3 & 36.4 \\
\hline Low transmission capacity & 64.3 & 44.4 \\
\hline High transmission capacity & 66.7 & 28.6 \\
\hline
\end{tabular}

Notes: Column (1) shows which countries have been used in the computation of the pairwise convergence test, where: "All" means all countries, "No hub" ("Hub") denotes countries without (with) a trading hub, "Poor, inactive or no hub" ("Mature or active hubs") indicates the classification countries based on hub maturity discussed in Section 2.1 (see EFET, 2016; Heather and Petrovich, 2017), "Low transmission capacity" ("High transmission capacity") indicates countries that have transmission capacity below (above) the 2017 median transmission capacity (source: 2017 ENTSOG Capacity map dataset:https://www.entsog.eu). For further details see notes to Table 2. 
A.4.4. Different price series: additional tables

Table A7

Pairwise convergence based on unit root tests - real prices: 1991:h1-2017:h1.

\begin{tabular}{|c|c|c|c|c|c|c|c|c|}
\hline & \multicolumn{4}{|l|}{$5 \%$} & \multicolumn{4}{|l|}{$10 \%$} \\
\hline & (1) & (2) & (3) & (4) & (5) & (6) & $(7)$ & $(8)$ \\
\hline & AIC & $\% t$ & SIC & $\% t$ & AIC & $\% t$ & SIC & $\% t$ \\
\hline \multicolumn{9}{|l|}{ (a) ADF test } \\
\hline Const & 39.6 & 27.8 & 33.0 & 33.3 & 51.6 & 27.7 & 48.4 & 29.5 \\
\hline Const/trend & 50.5 & 21.7 & 41.8 & 26.3 & 64.8 & 22.0 & 57.1 & 25.0 \\
\hline \multicolumn{9}{|c|}{ (b) DF-GLS test } \\
\hline Const & 35.2 & 37.5 & 30.8 & 35.7 & 45.1 & 39.0 & 39.6 & 41.7 \\
\hline Const/trend & 40.7 & 32.4 & 37.4 & 29.4 & 51.6 & 34.0 & 49.5 & 33.3 \\
\hline \multicolumn{9}{|c|}{ (c) ADF-WS test } \\
\hline Const & 40.7 & 40.5 & 40.7 & 40.5 & 44.0 & 42.5 & 44.0 & 42.5 \\
\hline Const/trend & 44.0 & 37.5 & 44.0 & 37.5 & 52.7 & 35.4 & 52.7 & 35.4 \\
\hline
\end{tabular}

Notes: See notes to Table 2.

Table A8

Pairwise convergence based on unit root tests - with backcast of new methodology values during the old methodology period:h1 1991:h1-2017:h1.

\begin{tabular}{|c|c|c|c|c|c|c|c|c|}
\hline & \multicolumn{4}{|l|}{$5 \%$} & \multicolumn{4}{|l|}{$10 \%$} \\
\hline & (1) & $(2)$ & (3) & (4) & (5) & (6) & (7) & $(8)$ \\
\hline & AIC & $\% t$ & SIC & $\% t$ & AIC & $\% t$ & SIC & $\% t$ \\
\hline \multicolumn{9}{|l|}{ (a) ADF test } \\
\hline Const & 34.1 & 45.2 & 33.0 & 43.3 & 50.5 & 37.0 & 42.9 & 41.0 \\
\hline Const/trend & 51.6 & 29.8 & 46.2 & 31.0 & 62.6 & 29.8 & 59.3 & 29.6 \\
\hline \multicolumn{9}{|c|}{ (b) DF-GLS test } \\
\hline Const & 50.5 & 41.3 & 45.1 & 43.9 & 67.0 & 39.3 & 62.6 & 40.4 \\
\hline Const/trend & 51.6 & 40.4 & 46.2 & 42.9 & 65.9 & 40.0 & 58.2 & 43.4 \\
\hline \multicolumn{9}{|c|}{ (c) ADF-WS test } \\
\hline Const & 52.7 & 39.6 & 52.7 & 39.6 & 69.2 & 38.1 & 69.2 & 38.1 \\
\hline Const/trend & 51.6 & 40.4 & 51.6 & 40.4 & 64.8 & 40.7 & 64.8 & 40.7 \\
\hline
\end{tabular}

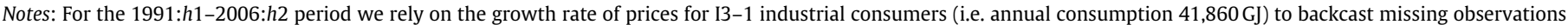
for prices for Band $\mathrm{I} 3$ consumers (i.e., consumption of 10,000-100,000 gigajoules per year). See notes to Table 2.

Table A9

Pairwise convergence based on unit root tests: 1996:h1-2017:h1.

\begin{tabular}{|c|c|c|c|c|c|c|c|c|}
\hline & \multicolumn{4}{|l|}{$5 \%$} & \multicolumn{4}{|l|}{$10 \%$} \\
\hline & (1) & (2) & (3) & (4) & (5) & (6) & (7) & $(8)$ \\
\hline & AIC & $\% t$ & SIC & $\% t$ & AIC & $\% t$ & SIC & $\% t$ \\
\hline \multicolumn{9}{|l|}{ (a) ADF test } \\
\hline Const & 37.4 & 47.1 & 45.1 & 46.3 & 60.4 & 41.8 & 62.6 & 43.9 \\
\hline const/trend & 39.6 & 44.4 & 46.2 & 45.2 & 58.2 & 43.4 & 64.8 & 42.4 \\
\hline \multicolumn{9}{|c|}{ (b) DF-GLS test } \\
\hline Const & 45.1 & 51.2 & 46.2 & 54.8 & 62.6 & 47.4 & 61.5 & 50.0 \\
\hline Const/trend & 56.0 & 41.2 & 61.5 & 41.1 & 70.3 & 42.2 & 72.5 & 42.4 \\
\hline \multicolumn{9}{|c|}{ (c) ADF-WS test } \\
\hline Const & 56.0 & 47.1 & 56.0 & 47.1 & 62.6 & 47.4 & 62.6 & 47.4 \\
\hline Const/trend & 57.1 & 46.2 & 57.1 & 46.2 & 70.3 & 42.2 & 70.3 & 42.2 \\
\hline
\end{tabular}

Notes: See notes to Table 2. 
Table A10

Pairwise convergence based on unit root tests - after tax prices: 1991:h1-2017:h1.

\begin{tabular}{|c|c|c|c|c|c|c|c|c|}
\hline & \multicolumn{4}{|l|}{$5 \%$} & \multicolumn{4}{|l|}{$10 \%$} \\
\hline & (1) & $(2)$ & (3) & (4) & (5) & (6) & (7) & (8) \\
\hline & AIC & $\% t$ & SIC & $\% t$ & AIC & $\% t$ & SIC & $\% t$ \\
\hline \multicolumn{9}{|l|}{ (a) ADF test } \\
\hline Const & 28.6 & 26.9 & 19.8 & 22.2 & 44.0 & 27.5 & 30.8 & 35.7 \\
\hline Const/trend & 46.2 & 16.7 & 31.9 & 13.8 & 59.3 & 20.4 & 49.5 & 22.2 \\
\hline \multicolumn{9}{|c|}{ (b) DF-GLS test } \\
\hline Const & 36.3 & 24.2 & 26.4 & 29.2 & 52.7 & 25.0 & 42.9 & 30.8 \\
\hline Const/trend & 44.0 & 20.0 & 33.0 & 23.3 & 69.2 & 19.0 & 54.9 & 24.0 \\
\hline \multicolumn{9}{|c|}{ (c) ADF-WS test } \\
\hline Const & 44.0 & 27.5 & 44.0 & 27.5 & 52.7 & 25.0 & 52.7 & 25.0 \\
\hline Const/trend & 47.3 & 25.6 & 47.3 & 25.6 & 69.2 & 19.0 & 69.2 & 19.0 \\
\hline
\end{tabular}

Notes: See notes to Table 2.

\section{A.5. Persistence profiles: estimation and further details}

Persistence profiles (PPs) are formally defined as the scaled difference between the conditional variance of $M$-step and ( $M$ - 1)-step ahead forecasts. Formally:

$$
\mathbf{\Omega}(M)=\operatorname{Var}\left(\mathbf{y}_{t+M} \mid \mathcal{I}_{t-1}\right)
$$

where $\mathbf{\Omega}(M)$ denotes the conditional variance of $2 \times 1$ vector of log-prices $\mathbf{y}_{t}$ and $\mathcal{I}_{t-1}$ is the information set at time $t-1$. Notice that when $\mathbf{y}_{t}$ has a unit root, $\boldsymbol{\Omega}(M)$ increases without bound. Therefore, to accommodate unit-root variables in the system Lee and Pesaran (1993) suggested to focus on:

$$
\Delta \boldsymbol{\Omega}(M)=\mathbf{\Omega}(M)-\mathbf{\Omega}(M-1)
$$

that tends to zero as $M \rightarrow \infty$ if $\mathbf{y}_{t}$ is stationary and tends to a non-negative constant if there is a unit root variable in $\mathbf{y}_{t}$. PPs are graphically represented as a plot of $\Delta \boldsymbol{\Omega}(M)$ against the forecast horizon $M$. PPs are thus "variance-based" measures of the persistence of shocks to the system at different time horizons.

There are two main differences between PPs and impulse-response functions (IRF). First, IRFs trace the effect of a particular shock on a given variable, while PPs focus on the time profile of a system-wide shocks on the cointegrating relation. For this reason, interpretation of PPs does not require to orthogonalize the covariance matrix of the shocks, which is often viewed as the most critical part of structural IRF analysis.

For each pair of countries we estimate PPs after reparameterizing a VAR model for the log-prices as a Vector Error Correction Model (VECM). In our application, we impose a lag order of $p=2$ in the VAR model, implying the existence of one lag in the VECM representation. Estimation of the VECM relies on the approach due to Johansen (1991).

\section{References}

Apergis, N., Bowden, N., Payne, J.E., 2015. Downstream integration of natural gas prices across US states: evidence from deregulation regime shifts. Energy Econ. 49, 82-92.

Asche, F., Misund, B., Sikveland, M., 2013. The relationship between spot and contract gas prices in Europe. Energy Econ. 38, 212-217.

Asche, F., Oglend, A., Osmundsen, P., 2017. Modeling UK natural gas prices when gas prices periodically decouple from the oil price. Energy J. 38 (2), 131-148.

Asche, F., Osmundsen, P., Tveteras, R., 2002. European market integration for gas? Volume flexibility and political risk. Energy Econ. 24 (3), 249-265.

Auping, W., Pruyt, E., de Jong, S., Kwakkel, J., 2016. The geopolitical impact of the shale revolution: exploring consequences on energy prices and rentier states. Energy Policy 98, 390-399.

Bachmeier, L.J., Griffin, J.M., 2006. Testing for market integration crude oil, coal, and natural gas. Energy J. 27 (2), 55-71.

Barrett, C.B., 1996. Market analysis methods: are our enriched toolkits well suited to enlivened markets? Am. J. Agric. Econ. 78 (3), 825-829.

Barrett, C.B., Li, J.R., 2002. Distinguishing between equilibrium and integration in spatial price analysis. Am. J. Agric. Econ. 84 (2), 292-307.

Bastianin, A., Castelnovo, P., Florio, M., 2018. Evaluating regulatory reform of network industries: a survey of empirical models based on categorical proxies. Util. Policy $55,115-128$.

Bernard, A.B., Durlauf, S.N., 1995. Convergence in international output. J. Appl. Econ. 10 (2), 97-108.

Bernard, A.B., Durlauf, S.N., 1996. Interpreting tests of the convergence hypothesis. J. Econ. $71(1-2), 161-173$
Brau, R., Doronzo, R., Fiorio, C.V., Florio, M., 2010. EU gas industry reforms and consumers' prices. Energy J. 34 (4), 167-182.

Brown, S.P., Yücel, M.K., 2009. Market arbitrage: European and North American natural gas prices. Energy J. 30, 167-185.

Bunzel, H., Vogelsang, T.J., 2005. Powerful trend function tests that are robust to strong serial correlation, with an application to the Prebisch-Singer hypothesis. J. Bus. Econ. Stat. 23 (4), 381-394

Caporin, M., Fontini, F., 2017. The long-run oil-natural gas price relationship and the shale gas revolution. Energy Econ. 64, 511-519.

Cavanagh, C.L., Elliott, G., Stock, J.H., 1995. Inference in models with nearly integrated regressors. Econ. Theory 11 (5), 1131-1147.

Cheung, Y.-W., Lai, K.S., 1998. Parity reversion in real exchange rates during the post-Bretton Woods period. J. Int. Money Financ. 17 (4), 597-614.

Cheung, Y.-W., Lai, K.S., 2009. Practitioners corner: lag order and critical values of a modified Dickey-Fuller test. Oxf. Bull. Econ. Stat. 57 (3), 411-419.

Cremer, H., Laffont, J.J., 2002. Competition in gas markets. Eur. Econ. Rev. 46, 928-935. Cuddington, J.T., Wang, Z., 2006. Assessing the degree of spot market integration for U.S. natural gas: evidence from daily price data. J. Regul. Econ. 29 (2), 195-210.

De Vany, A., Walls, W., 1993. Pipeline access and market integration in the natural gas industry: evidence from cointegration tests. Energy J. 14 (4), 1-20.

del Valle, A., Due nas, P., Wogrin, S., Reneses, J., 2017. A fundamental analysis on the implementation and development of virtual natural gas hubs. Energy Econ. 67, 520-532.

Dickey, D.A., Fuller, W.A., 1979. Distribution of the estimators for autoregressive time series with a unit root. J. Am. Stat. Assoc. 74 (366a), 427-431.

EFET, 2016. Review of gas hub assessment. https://www.efet.org. Available online at (last accessed November, 2017) 
EIA, 2017. International Energy Outlook 2017. U.S. Energy Information Administration. Elliott, G., 1998. On the robustness of cointegration methods when regressors almost have unit roots. Econometrica 66 (1), 149-158.

Elliott, G., Rothenberg, T.J., Stock, J.H., 1996. Efficient tests for an autoregressive unit root. Econometrica 64 (4), 813-836.

Fackler, P.L., Goodwin, B.K., 2001. Spatial price analysis. In: Gardner, B.L., Rausser G.C. (Eds.), Handbook of Agricultural Economics. vol. 2. Elsevier., pp. 971-1024. Chapter 17.

Foucault, T., Pagano, M., Rüell, A., 2013. Market Liquidity: Theory, Evidence, and Policy. Oxford University Press.

Growitsch, C., Stronzik, M., Nepal, R., 2015. Price convergence and information efficiency in german natural gas markets. Ger. Econ. Rev. 16 (1), 87-103.

Hartley, P.R., Medlock, K.B., III, Rosthal, J.E., 2008. The relationship of natural gas to oil prices. Energy J. 29 (3), 47-66.

Heather, P., 2012. The Evolution of European Traded Gas Hubs. OIES paper NG 104. Oxford Institute for Energy Studies.

Heather, P., 2015. Continental European Gas Hubs: Are They Fit for Purpose? OIES paper NG 63. Oxford Institute for Energy Studies.

Heather, P., Petrovich, B., 2017. European Traded Gas Hubs: An Updated Analysis on Liquidity, Maturity and Barriers to Market Integration. Energy Insight 13. Oxford Institute for Energy Studies.

Hodrick, R.J., Prescott, E.C., 1997. Postwar US business cycles: an empirical investigation. J. Money, Credit, Bank. 29 (1), 1-16.

Hulshof, D., van der Maat, J.-P., Mulder, M., 2016. Market fundamentals, competition and natural-gas prices. Energy Policy 94, 480-491.

Jadidzadeh, A., Serletis, A., 2017. How does the US natural gas market react to demand and supply shocks in the crude oil market? Energy Econ. 63, 66-74.

Johansen, S., 1991. Estimation and hypothesis testing of cointegration vectors in Gaussian Vector Autoregressive models. Econometrica 59 (6), 1551-1580.

Kapetanios, G., Shin, Y., Snell, A., 2003. Testing for a unit root in the nonlinear STAR framework. J. Econ. 112 (2), 359-379.

Kilian, L., 2017. The impact of the fracking boom on Arab oil producers. Energy J. 38 (6), 137-160.

King, M., Cuc, M., 1996. Price convergence in North American natural gas spot markets. Energy J. 17 (2), 17-42.

Knetter, M.M., Slaughter, M.J., 2001. Measuring product-market integration. In: Blomstrom, M., Goldberg, L.S. (Eds.), Topics in Empirical International Economics: A Festschrift in Honor of Robert E. Lipsey. University of Chicago Press, pp. 15-46. chapter 1.

Koske, I., Wanner, I., Bitetti, R., Barbiero, O., 2015. The 2013 update of the OECD's database on product market regulation. Working Paper 1200. OECD Economics Department.

Koster, H.R., van Ommeren, J., 2015. A shaky business: natural gas extraction, earthquakes and house prices. Eur. Econ. Rev. 80, 120-139.

Lee, K.C., Pesaran, M.H., 1993. Persistence profiles and business cycle fluctuations in a disaggregated model of UK output growth. Ric. Econ. 47 (3), 293-322.

Leybourne, S., Kim, T.-H., Newbold, P., 2005. Examination of some more powerful modifications of the Dickey-Fuller test. J. Time Ser. Anal. 26 (3), 355-369.

Li, R., Joyeux, R., Ripple, R.D., 2010. International steam coal market integration. Energy J. 31 (3), 181-202.
Li, R., Joyeux, R., Ripple, R.D., 2014. International natural gas market integration. Energy J. 35 (4), 159-179.

MacKinnon, J.G., 1996. Numerical distribution functions for unit root and cointegration tests. J. Appl. Econ. 11 (6), 601-618.

Miriello, C., Polo, M., 2015. The development of gas hubs in Europe. Energy Policy 84, 177-190.

Mu, X., Ye, H., 2018. Towards an integrated spot LNG market: an interim assessment. Energy J. 39 (1), 211-233.

Neumann, A., 2009. Linking natural gas markets - is LNG doing its job? Energy J. 30, 187-199.

Neumann, A., Siliverstovs, B., von Hirschhausen, C., 2006. Convergence of European spot market prices for natural gas? A real-time analysis of market integration using the kalman filter. Appl. Econ. Lett. 13 (11), 727-732.

Newey, W.K., West, K.D., 1987. A simple, positive semi-definite, heteroskedasticity and autocorrelation consistent covariance matrix. Econometrica 55 (3), 703-708.

Nick, S., Thoenes, S., 2014. What drives natural gas prices? - a structural VAR approach. Energy Econ. 45, 517-527.

Pantula, S.G., Gonzalez-Farias, G., Fuller, W.A., 1994. A comparison of unit-root test criteria. J. Bus. Econ. Stat. 12 (4), 449-459.

Park, H., Mjelde, J.W., Bessler, D.A., 2008. Price interactions and discovery among natural gas spot markets in North America. Energy Policy 36 (1), 290-302.

Park, H.J., Fuller, W.A., 1995. Alternative estimators and unit root tests for the autoregressive process. J. Time Ser. Anal. 16 (4), 415-429.

Perron, P., 1989. The Great Crash, the oil price shock, and the unit root hypothesis. Econometrica 57 (6), 1361-1401.

Pesaran, M.H., 2007. A pair-wise approach to testing for output and growth convergence. J. Econ. 138 (1), 312-355.

Pesaran, M.H., Shin, Y., 1996. Cointegration and speed of convergence to equilibrium. J. Econ. 71 (1-2), 117-143.

Pesaran, M.H., Smith, R.P., Yamagata, T., Hvozdyk, L., 2009. Pairwise tests of purchasing power parity. Econ. Rev. 28 (6), 495-521.

Phillips, P.C.B., Sul, D., 2007. Transition modeling and econometric convergence tests. Econometrica 75 (6), 1771-1855.

Ravn, M.O., Uhlig, H., 2002. On adjusting the Hodrick-Prescott filter for the frequency of observations. Rev. Econ. Stat. 84 (2), 371-376.

Renou-Maissant, P., 2012. Toward the integration of European natural gas markets: a time-varying approach. Energy Policy 51, 779-790.

Robinson, T., 2007. Have European gas prices converged? Energy Policy 35 (4), $2347-2351$.

Saussay, A., 2018. Can the US shale revolution be duplicated in continental Europe? An economic analysis of European shale gas resources. Energy Econ. 69, 295-306.

Serletis, A., Herbert, J., 1999. The message in North American energy prices. Energy Econ. 21 (5), 471-483.

Siliverstovs, B., L'Hégaret, G., Neumann, A., von Hirschhausen, C., 2005. International market integration for natural gas? A cointegration analysis of prices in Europe, North America and Japan. Energy Econ. 27 (4), 603-615.

Stock, J., Watson, M., 2012. Disentangling the channels of the 2007-2009 recession. Brook. Pap. Econ. Act. Spring 2012, 81-135.

Zivot, E., Andrews, D.W.K., 2002. Further evidence on the Great Crash, the oil-price shock, and the unit-root hypothesis. J. Bus. Econ. Stat. 20 (1), 25-44. 